\title{
New Concept and Design of Electronically Controlled Cylinder Lubrication System for Large Two-Stroke Marine Diesel Engines
}

\author{
Yuhai $\mathrm{He}^{1,2, *}$, Peilin Zhou ${ }^{3}$, Liangtao Xie ${ }^{1}$ and Jiyun Zhang ${ }^{1,4}$ \\ ${ }^{1}$ School of Energy and Power Engineering, Wuhan University of Technology, 430063 Wuhan, PR \\ China. \\ ${ }^{2}$ Key Laboratory of Marine Power Engineering \& Technology under Minister of Communication PR \\ China, 430063 Wuhan, PR China. \\ ${ }^{3}$ Department of Naval Architecture, Ocean and Marine Engineering, University of Strathclyde, G4 \\ 0LZ Glasgow, UK. \\ ${ }^{4}$ Wuhan Sailinde Marine Technology Co., Ltd, 430223 Wuhan, PR China. \\ ${ }^{*}$ Corresponding author: Yuhai He, School of Energy and Power Engineering, Wuhan University of \\ Technology, No.1178 Heping Avenue, Wuchang District, Wuhan City 430063, People's Republic of \\ China.Email: hyh@whut.edu.cn
}

\begin{abstract}
:
Lubrication of cylinders between liners and rings is one of the crucial factors that affects the efficient operation of diesel engines. Marine diesel engines usually use inferior heavy fuel oil with high sulphur content, and the acidic substances formed by fuel combustion need alkaline cylinder oil to neutralize. For the operational cost to a marine engine, besides fuel oil, cylinder oil also takes a big share. This article firstly analyses the advantages and disadvantages of existing cylinder lubrication systems with regard to oil injection control. Secondly, the control parameters and variables such as the oil injection pressure, timing, oil feed rate and reliability are analysed, and the corresponding control schemes formulated. Thirdly, the control strategies are developed in detail. Finally, verification tests are carried out on an actual engine, with the results showing that the control strategies developed in this article provide a stable, cost-effective, creative and excellent solution for cylinder lubrication with reduced cylinder wear. A thin and uniform oil film distribution is retained on the liner surface, with savings in cylinder oil consumption, lower particulate matter emission levels and improved cylinder liner and piston rings running conditions. The experimental results show that the oil consumption could be reduced by up to $50 \%$.
\end{abstract}

Keywords: Two-stroke diesel engine; Cylinder lubrication; Cylinder lube oil; Control strategy; Electronic control; Cylinder oil consumption reduction; Emission reduction

\section{Introduction}

The main propulsion system generally used for large-scale ships are the large-bore, low-speed, two-stroke and crosshead type marine diesel engines. ${ }^{1}$ With this type of diesel engine, the upper part of the engine frame 
comprises a diaphragm and a piston rod stuffing box, which separates the cylinder from the crankcase. This structural feature determines that an independent cylinder lubrication system (CLS) must be installed between the piston and the cylinder liner. In general, an engine is equipped with a number of lubricators, each supplying cylinder lubrication oil to one or more cylinders. ${ }^{2}$ The lubricators are designed to pump a specified quantity of cylinder oil to the cylinder liners and piston rings. The main purpose is to reduce wear and corrosion. Furthermore, the cylinder oil helps to seal the piston to prevent the loss of compression and combustion pressure.

In recent years, with the wide application of high supercharged and long-stroke engine, together with the increased use of high viscosity, low quality and high sulphur fuel oil, the cylinder oil consumption rate (COCR) has risen sharply in order to ensure good lubrication of cylinder wall and neutralization of combustion products. ${ }^{3}$ Using some world-known shipping companies' statistics, regarding the cost of marine diesel engine's cylinder equipment; the cylinder liner accounts for $16 \%$, the piston $6 \%$, the piston ring $2 \%$, the maintenance cost $3 \%$ and the cylinder oil consumption $73 \%{ }^{4}$ Therefore, after saving in fuel consumption, controlling the consumption of cylinder oil becomes another significant way to reduce the operating cost of ships and protect the environment.

Generally, there are four types of CLS: timed lubrication system (TLS), accumulator principle (AP), Alpha lubrication (AL) and swirl injection principle (SIP). The detailed application research and development trend analysis are presented in Gao Bing et al. ${ }^{5}$ or Zheng Guojie et al. ${ }^{6}$ The control modes and strategies of the above four systems were analysed. However, the control of injection pressure is not the focus of attention because the injection pressure is supposed to be controlled by a conventional mechanical-hydraulic system (not by the proposed electronically controlled system).

A conventional type of mechanical lubricator is connected with a rotary drive to the engine. This drive secures synchronization with crankshaft movement giving the timed injection of the cylinder oil. A setting gauge allowing easy adjustment of the timing can be supplied for engines where applicable, as in Zhang Jiesheng. ${ }^{7}$ However, this can bring the biggest downside, resulting in a high COCR at part load conditions, as described in He Yuhai ${ }^{8}$ or Gao Bing. ${ }^{9}$ The reasons are as follows: on the one hand, most vessels are propelled by a slowspeed two-stroke engine directly coupled to a fixed pitch propeller. So, the correlation between speed and shaft power is not linear, but cubic. On the other hand, the oil pumping frequency synchronizes with the engine speed. So, it has a linear relationship with the engine speed, rather than a direct relationship with the engine load, the oil injection quantity is therefore mainly adjusted manually by changing the plunger stroke of each oil pump unit, and cannot automatically be adjusted in real time, resulting in higher COCR under low load conditions. Taking the marine diesel engine "MAN B\&W 6S60MC" as an example, the COCR set at $1.09 \mathrm{~g} /(\mathrm{kW} \cdot \mathrm{h})$ for $100 \%$ load, if the plunger stroke (i.e., the amount of circulating oil injection) remains unchanged, the COCR will increase to $1.52 \mathrm{~g} /(\mathrm{kW} \cdot \mathrm{h})$ at $60 \%$ load and $1.84 \mathrm{~g} /(\mathrm{kW} \cdot \mathrm{h})$ at $45 \%$ load. ${ }^{10}$ Furthermore, the practice of deliberately slowing down the speed of a ship (That is to reduce the engine load greatly) is, in fact, a common operating feature of today's shipping market as a way to lower costs by reducing fuel consumption. With over lubrication, too much cylinder oil could cause scuffing due to stuck piston rings or cylinder oil absorption due to a significant amount of additives, even the scavenge box to catch fire as described in Zheng Weikang at al. ${ }^{11}$ Fortunately, this problem can be ameliorated with the addition of a modifier such as the one described by Zheng Guojie. ${ }^{6}$ The quantity of cylinder oil injected may be automatically and partially regulated by applying load change dependent (LCD) and /or mean effective pressure (MEP) regulation. Many researchers have studied the 
performance of the conventional mechanical lubricator. Some technical defects have been investigated by several authors, such as in the works by Chen Shaogang et al. ${ }^{2}$ or Gao Bing et al. ${ }^{5}$ Xu Guoxin ${ }^{12}$ or He Yuhai. ${ }^{13}$ reported a notable increase in the COCR and reasoned that the lubricator cannot adapt to reflect changes in the actual working conditions of the engine and achieve the best cylinder oil feed rate (COFR). Zhang Congde et al. ${ }^{14}$ also confirmed that its COFR cannot be automatically adjusted consequent upon the sulphur content of the heavy fuel oil (H.F.O.), the alkalinity of cylinder oil and the running status of the main engine. Cylinder oil injection quantity and timing have been measured in Chen Zhijun, ${ }^{10}$ where the results showed that the timing of the injection is not very precise and the amount of cylinder oil injected is not sufficiently uniform. The oil injection pressure has also been recorded and shown to be relatively low, resulting in poor lubrication on the cylinder liner wall, as investigated in Su Zhonglin. ${ }^{15}$ The cylinder oil injection is unstable especially when the main engine is operating at low speed or under low load, as described in Bao Junhui. ${ }^{16}$

SIP lubricating is a brand new concept for cylinder lubrication developed by Danish Hans Jensen Lubricator A/S (HJL). SIP cylinder lubricator can be driven from the engine crankshaft or by an electric motor to achieve three kinds of control mode, i.e., the synchronization, asynchronization and interval type. The cylinder oil is pressured and atomized through the SIP valve nozzle and then sprayed as an atomized oil mist along the surface of the cylinder liner wall. The scavenging air swirl further spread atomized oil mist to evenly cover the whole area of the upper cylinder wall before the arrival of the piston rings. HJL SIP system is also equipped with an MEP or LCD regulator to make up for the deficiencies of the load-independent cylinder lubrication. However, SIP lubricator cannot make up for the deficiencies of the conventional mechanical cylinder lubricator, as investigated in the literature, ${ }^{15,17}$ where the properties of back-pressure timing, loadindependent cylinder lubrication and the tendency in the long-term for eccentric wear of the cylinder liner wall are presented and discussed. As a retrofit on vessels in service, the cylinder liner needs to be modified with a small jet slot to replace the traditional polyline groove. ${ }^{18}$

CLU series CLS is currently one of the mainstream products on the marine diesel engine market and mainly used for the Wärtsilä diesel engine. The latest CLU-4 and CLU-5 pulse feed lubrication system is based on a lubrication module with integrated electronics and newly developed lubricators, as described in Chen Zhongru ${ }^{19}$ and Ling Gangyi et al. ${ }^{20}$ Cylinder oil is not atomized by the lubricating quills (i.e. nozzle, a built-in non-return valve). Cylinder oil injection takes place during compression strokes only. The vertical oil distribution is determined by cylinder oil injection timing. Only one injection takes place per one stroke of the piston: either "above", "into" or "below" - decided by pulse lubrication system (PLS) control system, as shown in Figure 1. The number of strokes without any injection depends on the Engine load. Cylinder lubricators ("quills") deliver the cylinder oil as compact pulse feed into preselected areas of the piston. The vertical oil distribution can be adjusted (not from the operator's level). The commonly used pattern is $40 \% / 40 \% / 20 \%$ for "above"/ "into ring pack"/ "below". From there, the cylinder oil is distributed around the circumference of the cylinder liner. That is, cylinder oil distribution into the piston ring pack to lubricate piston rings and the upper part of the liner, and cylinder oil distribution to piston skirt to lubricate lower part of the liner. This control mode replaces the multilevel CLS used in some of the old Wärtsilä engines, fosters optimum distribution of the cylinder oil and adapts to the longer stroke. However, some deficiencies in the CLU series CLS have been proven in numerous research projects. For example, the CLU-3 system still uses quills of accumulator type, resulting in inaccurate lubrication 
timing, as identified in Chen Zhijun. ${ }^{10}$ In the CLU-4 system, although the pressure accumulator has been eliminated, the retrofit type nozzles need to be replaced, as spotted in Chen Zhongru. ${ }^{19}$

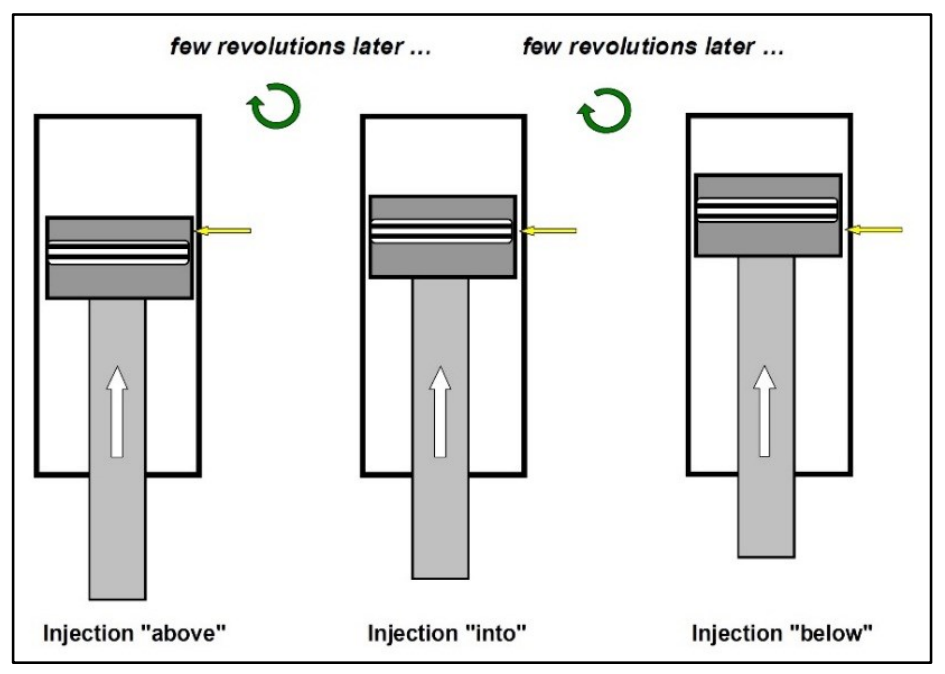

Figure 1. Schematic diagram of cylinder oil injection control

A lot of improvements have been seen in the field of cylinder lubrication during the last decade, as shown in the works by Gao Bin, ${ }^{21}$ Yao Shimin et al..$^{22}$ or Yang Yongjian et al. ${ }^{23}$ Furthermore, some advances developed in the electronically controlled approach can be found in the works of Lu Lin et al, ${ }^{24}$ He Yuhai et al. ${ }^{25,26,27}$ or Chen Zhijun et al. ${ }^{28,29}$ The Alpha lubricator, developed by MAN Diesel \& Turbo, automatically controls the timing and quantity of cylinder oil, and injects in fan shape onto the cylinder wall and piston rings, and its power comes from a specialized pumping station or common rail. Subsequently, this company introduced the Alpha adaptive cylinder-oil control (Alpha ACC) ECCLS with a better performance. ${ }^{30}$ According to the latest algorithm controlling cylinder oil dosage, the cylinder oil dosage must not only be proportional to the sulphur percentage in the fuel but also to the engine load. In order to achieve this algorithm, the specific COFR is controlled by the variation of the injection frequency. The lubrication principle is one of intermittent lubrication where an engine cycle with cylinder oil injection is followed by one or more (normally four cycles and up to 15 cycles without oil injection). However, an algorithm which only activates the cylinder oil dosage based on the amount of sulphur entering the cylinders is flawed. All factors that affect cylinder lubrication and neutralization must be taken into account, such as total base number (TBN) of cylinder oil, cylinder liners or piston rings running-in condition. It is also unreasonable to accept the principle of intermittent lubrication when the engine runs under low load conditions, and abnormal wear has been spotted by Cai Guanghui. ${ }^{31}$ The author concluded that insufficient cylinder oil leads to poor lubrication, but he could not find an explanation of this lubrication mechanism. Allowing up to 15 cycles without oil injection, risks the friction regimes of the surfaces between cylinder liner and piston rings becoming dry due to a shortage of cylinder oil. Various malfunction when in use can be found in the literature, where the faults of temperature control, parameters setting and false alarm et al. are reported and discussed, as can be seen in the works by Shi Qianghua et al. ${ }^{32}$ Wang Weifei, ${ }^{33}$ Li Guowei, ${ }^{34}$ Ren Baokun, ${ }^{35} \mathrm{Hu}$ Gang, ${ }^{36}$ Yang Xianming et al. ${ }^{37}$ Wang Lianhai et al. ${ }^{38}$ Xiong Shifeng et al. ${ }^{39}$ and Yan Wei et al. ${ }^{40}$ Especially mentioned about the influence of temperature on the considered characteristics under different loads are the works by Qi Wenzheng ${ }^{41}$ and Zhou Jiyou et al. ${ }^{42}$ In addition, Yang Yongjian et al. ${ }^{23}$ have 
identified the installation of the Alpha ACC system is very complicated, time-consuming and expensive, needing oil quill modification, cylinder liner modification (oil quill, larger holes and non-return valves), installation of an angle encoder and pick-up, insertion of non-return valves and T-pieces with end plugs in existing lubricator piping between the existing lubricator and the cylinder liner, and then the commissioning. Therefore, the Alpha ACC system is not suitable for retrofitting existing and older diesel engines.

In this article, an electronically controlled cylinder lubrication system (ECCLS) is developed with new strategies significantly different from the systems discussed above, that is to say, it utilizes the advantages of the CLSs described above. The article delivers a new method for ECCLS for application in large two-stroke marine diesel engines. The method is based on TLS with some aspects of AP. In this circumstances, the delivered method can be treated as an integrated method, which is more or less similar to AL. However, in comparison to $\mathrm{AL}$, there are some improvements. This article mainly investigates the requirements for proper control structure and control strategies for cylinder oil injection timing, COFR and safety protection, together with the hardware and software design of the system control unit. Finally, the results of ship trial tests of the designed system are presented.

\section{Control analysis}

\subsection{Control objectives}

CLSs have a significant influence on the anti-wear effect on cylinder liner and piston rings, neutralization of combustion products, cleaning, sealing, noise-reduction and effective cooling. It follows that they have a key role to play in improving engine cylinder oil consumption and reducing noxious exhaust emissions (especially particulate matter, PM). The following control characteristics should be sought to achieve these goals with a CLS.

\subsubsection{Injection pressure}

Injection pressures during the whole process should be above 2.0 MPa for a good injection formation; ${ }^{2}$ a tendency in practice to $4.0 \mathrm{MPa}$ and higher is noted. ${ }^{10}$ The higher injection pressure ensures that the droplets settle horizontally, and well distributed on the liner wall. This allows the piston rings to distribute the injected cylinder oil vertically, as they pass in the continuous upward movement.

\subsubsection{Injection timing}

Cylinder lubrication is timed so as to reduce oil consumption. Injection takes place when the exhaust valve is closing and well before the piston passes the injection quills in the upward movement. The control aim is to inject the cylinder oil exactly where and when it is needed: in the piston ring pack as it passes the cylinder oil quills. Thanks to the high pressure, it is possible to establish an injection period that starts just when the uppermost piston ring is passing the quills and ends exactly when the lowermost ring is passing. In addition, injection is to be in the tangential direction, ensuring the optimal distribution of oil over the complete ring pack and ring grooves. 
Furthermore, for a two-stroke diesel engine, the total injection duration should be 25 degrees of crank angle or less to achieving the maximum amount of cylinder oil injected into the piston ring pack. ${ }^{2}$

\subsubsection{Cylinder oil feed rate}

The main improvement sought for the new CLS with the introduction of an electronically controlled flexible oil dosage, is for a low total cylinder oil consumption while maintaining an excellent cylinder condition. The COFR is controlled with the engine load and varies as a function of engine condition. Electronically controlled adjustment of the COFR will also provide optimized and balanced lubrication, neutralization and PM emissions at all engine loads, speeds and other variables, particularly at part load.

\subsubsection{Reliability}

It is necessary to pre-lubricate the cylinders before the engine starts. ${ }^{43}$ This requires the CLS to feature a pre-injection control function. For safety reasons, the cylinder lubrication must be under the control of the condition evaluation system, giving a high level of automation and sensitive to engine load, fuel and cylinder oil quality, cylinder liner running-in condition, and even a total breakdown of electrical and other power supplies should not result in the engine stopping. ${ }^{44}$

\subsection{Control scheme}

An optimum distribution of oil is thus achieved with a minimum oil quantity injected. ${ }^{45}$ The cylinder lubricator pumps oil to the cylinder oil quills mounted in the cylinder liner wall. The quills are equipped with a nozzle for injecting tiny droplets of cylinder oil tangentially to the liner wall, covering a large area. Injecting from all quills ensures coverage of the entire circumference of the liner.

To ensure an effective lubrication, the cylinder oil quantity which is injected by the proposed electronically controlled cylinder lubricator is a constant value for each injection. This allows the cylinder oil to be distributed in very small amounts at each engine stroke, thereby creating an optimum oil film distribution. The lubrication principle is spacing lubrication which is that the lubricator injects cylinder oil once after a certain number of crankshaft revolutions; the injection rate is controlled by the new electronically controlled cylinder lubricator, which controlled by the stepper motor.

\subsubsection{Injection pressure}

The pumping station provides clean, temperature and pressure controlled cylinder oil for the electronically controlled cylinder lubricator which is a simplified oil-pump driven by a stepping motor and reserves the mechanical drive shaft. Thanks to a constant amount of oil being supplied per injection, it can guarantee high injection pressure even under low engine load. Apart from securing an adequate pressure for cylinder oil to become a suitable injection when leaving the nozzle, it also ensures that the cylinder oil in the pipe between cylinder lubricator and quills stays under adequate pressure.

The lubricator features a small plunger piston for each lubrication quill in the cylinder liner. Power for injecting the oil is derived from the stepping motor, driven from the $220 \mathrm{AC}$ ship supply. Equal amounts of oil 
are supplied to each quill and the highest possible safety margin against clogging of individual quills is secured.

The oil-pump plunger diameter is increased to satisfy the larger injection pressure per stroke, and improved sealing is introduced to prevent leaking. The drive capability of the stepping motor is increased to accept the larger torque from the oil pump.

\subsubsection{Injection timing}

Injection timing is based on the two signals coming from the crank angle encoder, one signal is a bottom dead centre (BDC) signal, and usually the BDC of the first cylinder marker, and another is the crankshaft position sensor signal, a crankshaft position trigger. This ensures the accuracy of injection timing. The new lubrication system is normally timed to inject oil into the piston ring pack during the compression.

\subsubsection{Cylinder oil feed rate}

The cylinder lubrication relies on injecting quantity-constant cylinder oil, by controlling the frequency of the stepper motor action; the main control unit (MCU) controls the injecting frequency of the new electronically controlled lubricator to maintain the most optimum COFR, which is controlled according to the engine load and can also be adjusted according to the engine condition. The basic COFR at maximum continuous rating (MCR, $100 \%$ load) is calculated as a correlation between a number of injections, revolutions per minute (RPM) and the stroke of the lubricators, and the stroke can be set by a screw, which limits the stroke of the main lubricator piston. Dosage is increased in line with load changes and as required by the cylinder condition monitoring system (e.g., in the event of liner scuffing and ring blow-by). Such systems are already available for existing engines.

The injecting frequency is calculated through the accelerator scale of the fuel pump and the speed of the main engine. According to operating conditions, different modes may be introduced into the calculation. The modes are: LCD mode ( $P_{e}$ mode), MEP mode $\left(P_{m e}\right.$ mode) and RPM mode ( $n$ mode), taking the injection rate as proportional to power, mean effective pressure and speed.

The MCU of electronically controlled lubricator receives the main engine crank angle signal from the angle encoder (the BDC signal), the engine speed signal, the engine load signal from the load transmitter, fuel sulphur content and other digital signals, and then works out the injection timing and frequency according to the set control mode to control a stepper motor and achieve the accuracy of cylinder oil injection. On the human machine interface (HMI), the COCR may be adjusted from $50 \%$ to $200 \%$ according to cylinder liner running state; the base value of the system determined is $100 \%$.

\subsubsection{Reliability}

Pre-lubrication of the cylinder can be done just before the start of the engine. A pressure switch sensor is fitted on the injection tubing near the nozzle; the sensor monitors the running state of electronically controlled cylinder lubricator in real time to ensure system reliability and dynamical correct of the injection timing.

When operating normally, the entire system is controlled by the MCU. Should the security and alarm system unit detect a failure on the control unit, they will alert and display alarm parameters in detail on the HMI panel. 
If a serious fault is detected on the MCU, the standby control unit (SCU) will take over automatically and "SCU in control" will light on the control panel at the same time. The SCU is based on random timing and RPM mode. The injection frequency is adjustable on the SCU and is normally, as a minimum, set to the basic COFR for the engine, plus $50 \%$.

If the SCU also fails, the system may be restored to mechanical lubricator operation mode by the "electronically controlled/ machine-controlled" switching device (effective only if the electronically controlled upgrade of the main engine has retained the mechanical lubricator).

\section{Control strategy}

The core variables of ECCLS, to meet cylinder lubrication requirements, are to control the cylinder oil injection timing, quantity (i.e., frequency) and reliability. Injection pressure depends mainly on the mechanical and hydraulic system on the stepper motor having sufficient torque to meet the system requirements.

The new ECCLS consisted of the following four parts, as shown in Figure.2: (1) Main control unit (MCU), (2) Lubricator unit (Lub.U), (3) Electronical / Mechanical control switching device (E/M CSD), (4) Oil-feed Unit (OFU). The original mechanical lubricator is retained and a device is installed to switch between the mechanical lubricator and the new lubrication system. That is, when the new ECCLS is working, cylinder oil pumped by the mechanical lubricator will bypass back to the tank, and the new lubricator injects oil into the cylinder.

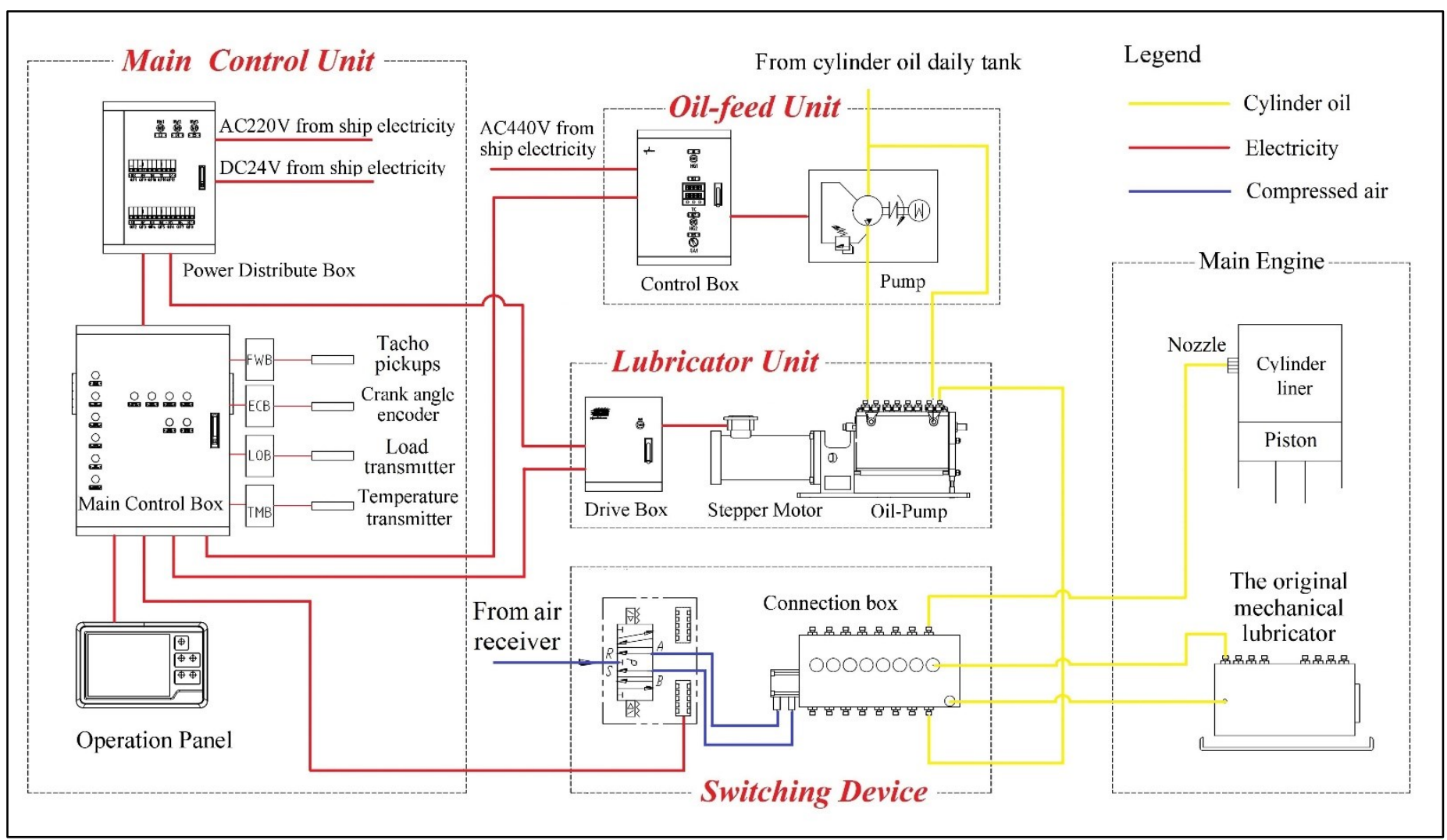

Figure 2. The composition and principle diagram of the new ECCLS 


\subsection{Injection timing}

For optimal oil injection timing: the cylinder oil injection should begin when the piston goes up and the first piston ring just passes across the oil quill, and end with the last piston ring passing through the oil quill.

\subsubsection{Logic control algorithm}

There is not any mechanical drive between the ECCLS and the marine engine crankshaft, the cylinder oil injection timing is based on two signals from the crank angle encoder. The logic control algorithm diagram of cylinder oil injection timing is shown in Figure 3.

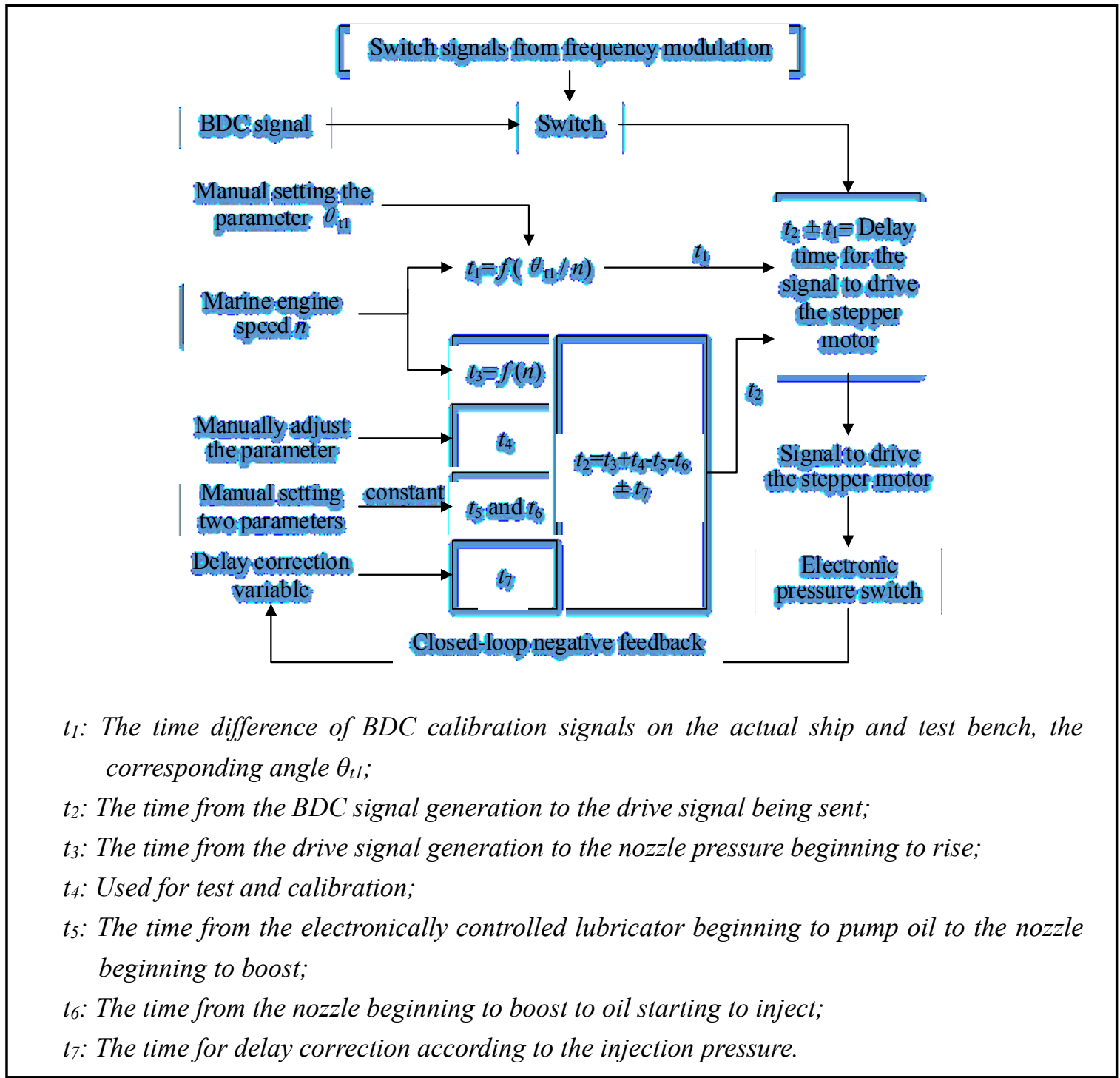

Figure 3. The diagram of cylinder oil injection timing control logic

\subsubsection{Delay correction through closed-loop control}

Quite a complex cylinder lubrication conditions prevail during engine operation. Theoretically, oil injection timing cannot completely meet the actual needs, due to changes in the viscosity of the cylinder oil, the length of the oil supply pipes and the lubricator itself, etc. 
The controller is used to control the stepper motor in order to achieve cylinder oil injection. The electric delay characteristics of the stepper motor should be taken into account, as well as any hydraulic delay in the pipeline. When the controller sends a control signal, there is a time delay until the nozzle actually begins to inject, as shown in Figure 4.

In order to deal with the issue of electric and hydraulic delay, it is necessary to correct the timed occurrence of the stepper motor's control signal. This system introduces the negative feedback and the ruler of the delay time.

An electronic pressure switch is installed close to the nozzle. When the stepper motor's control signal is sent, the controller will immediately start the timer until the pressure switch feedback signal is received. This period of time $t(\mathrm{~s})$ is the stepper motor's and the pipeline's delay time, and for the next injection, the control signal will advance $t(\mathrm{~s})$ to the stepper motor time. The controller, according to the BDC signal from the test board, can then determine the target starting time of cylinder oil injection. As for the timing scale, if the injection signal collected coincides with the target injection point time (accurate to $1 \mathrm{~ms}$ ), then the oil injection timing is correct. 


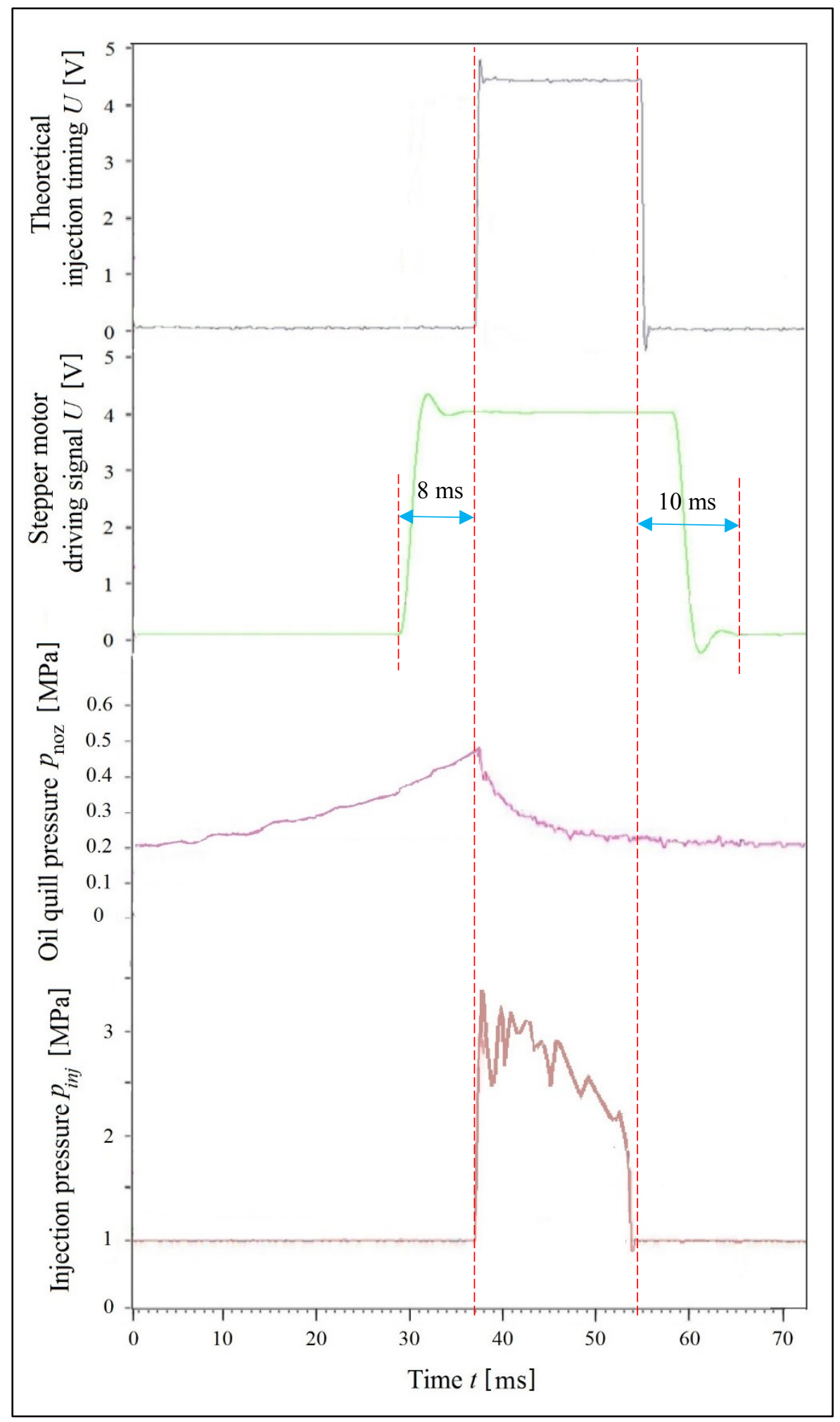

Figure 4. Cylinder oil injection timing

The above Figure 4 shows that the oil injection timing is very accurate, with the stepper motor's drive signal $9.5 \mathrm{~ms}$ in advance. The oil injection pressure is about 3.0 MPa and the oil injection duration is $16 \mathrm{~ms}$.

Dynamic correction ensures that every injection timing is in the target injection band. The advantages of the dynamic modification when compared with the traditionally fixed amount injection timing include: 
(1) The traditional way to solve the delay time is by taking a fixed calibration delay time, but its shortcoming is that only reflects the delay time of the calibration speed and do not reflect the dynamic changes of the delay time following speed changes.

(2) The dynamic adjustment of delay time, not only can correct the delay caused by the stepper motor and piping but can also correct the delay caused by other reasons, such as changes in oil pressure or oil temperature.

\subsection{Injection frequency}

As the main factor of cylinder liner wear is of a corrosive nature, the amount of neutralising alkaline components needed in the cylinder will, therefore, be proportional to the amount of sulphur - which generates sulphurous acids - entering the cylinders. A minimum cylinder oil dosage needs to be set, in order to satisfy the other requirements of a lubricant, such as providing an adequate oil film and detergency properties.

The cylinder oil dosage is controlled according to the amount of sulphur entering the cylinder with the fuel. The cylinder oil dosage must then be proportional to the sulphur percentage in the fuel and the engine load. Implementation of the above two criteria leads to an optimal cylinder oil dosage.

\subsubsection{Logic control algorithm}

The cylinder oil consumption significantly increased when the main engine is working under off-rating conditions, especially in part load conditions (such as the ship in ballast). Looking back the diesel fuel injection system, that is Bosch high-pressure pump's working principle, the root cause is that the effective oil-pumping stroke of the plunger can't automatically adjust in real time as operating conditions change. However, the new ECCLS does not use the Bosch high-pressure pump plunger chute method or another electronically controlled way to change the cycle injection quantity to control the COCR, which is so-called the amplitude modulation control strategy. The control method of cylinder oil injection is frequency modulation. The logic control algorithm diagram of cylinder oil injection frequency is shown in Figure 5. 


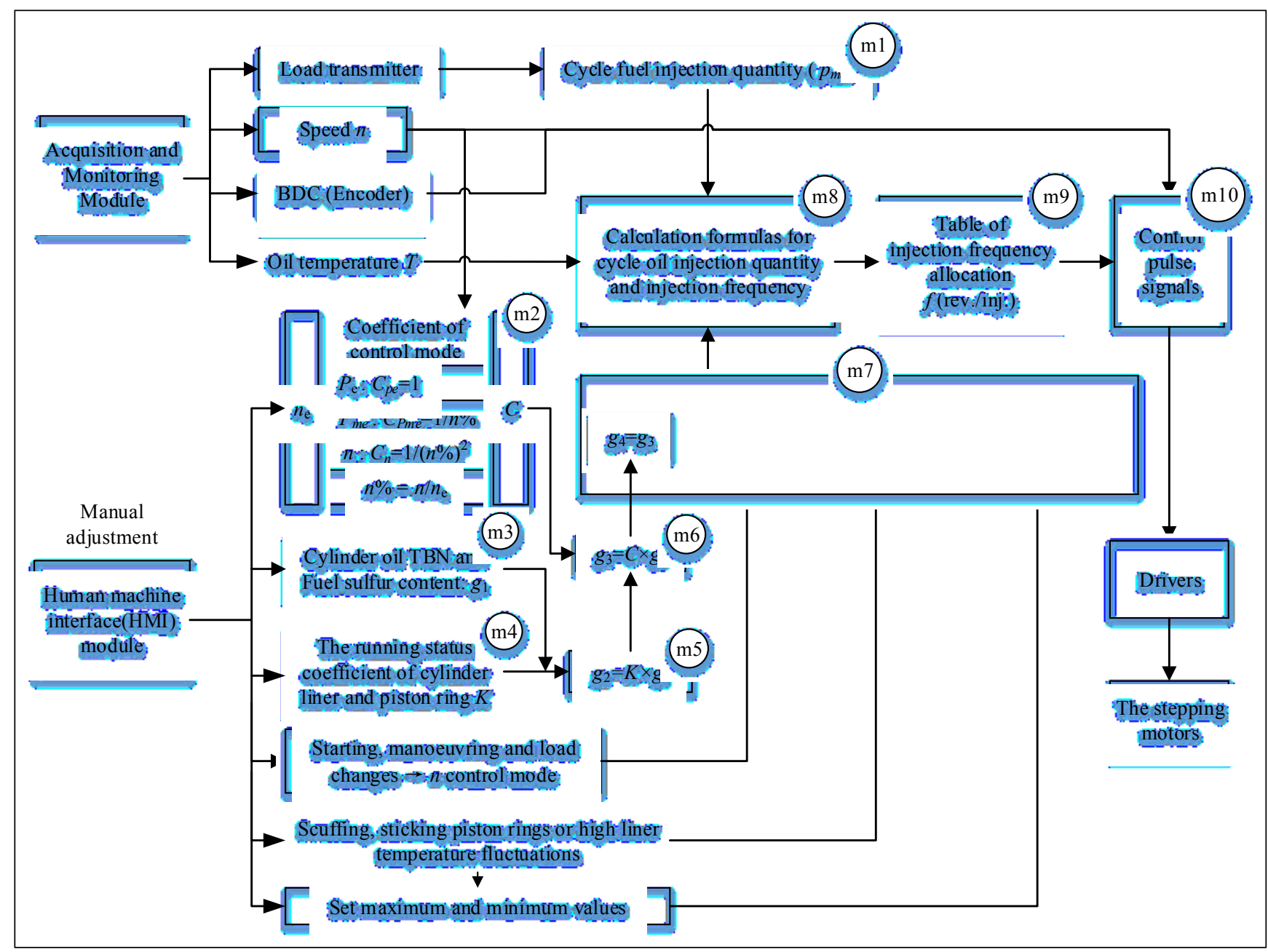

Figure 5. The diagram of cylinder oil injection frequency control logic

\subsubsection{Main MAPs control strategy and data}

As shown in Figure 5 above, the MCU receipts the marine engine's crank angle signal, speed, BDC or top dead centre (TDC) signal from the encoder, and also receipts the marine engine's load transmitter signal; At the same time, the MCU records the parameters set on HMI, such as the fuel sulphur content, control model and cylinder liner running state. After processing, the MCU will send the injection frequency signal to control the stepper motor achieving the accurate cylinder oil injection.

\section{(1) MAP.1 (m1)}

Changes in the position of the fuel regulation shaft reflect engine load changes. If these changes are smaller than a pre-set reference, no lubrication adjustment will be made, to avoid frequent changes in the injection frequency. If the changes are larger than the pre-set reference value, lubrication is increased or decreased according to engine load. The stepper motor drives and controls the oil-pump injection frequency. This will enable it to fine-tune the amount of the cylinder oil provided to all oil-pumps in the lubrication system.

The effective thermal efficiency curve of a large low-speed two-stroke diesel engine is relatively flat. ${ }^{2}$ When the load is increased from $50 \%$ to $100 \%$, the maximum change in effective thermal efficiency does not exceed $5 \%$ and the average value does not exceed $2.5 \%{ }^{2}$ Therefore, it is appropriate to set the mean effective 
pressure $p_{\text {me }}$ proportional to the amount of fuel injected per cycle.

The relationship between the fuel index signal and the rack position of the fuel pump is calibrated according to the structure of the fuel regulation shaft, and the relationship between the rack position of the fuel pump and $p_{\text {me }}$ can be found in the engine operating manual or test report. By inputting a variable 'the position of the fuel regulation shaft $R(\mathrm{~mm})$ ' and outputting a variable 'MEP $p_{\mathrm{me}}(\mathrm{MPa})$ ', as a result, MAP.1 can be obtained. Figure 6 is an example of this relationship curve for one type of engine.

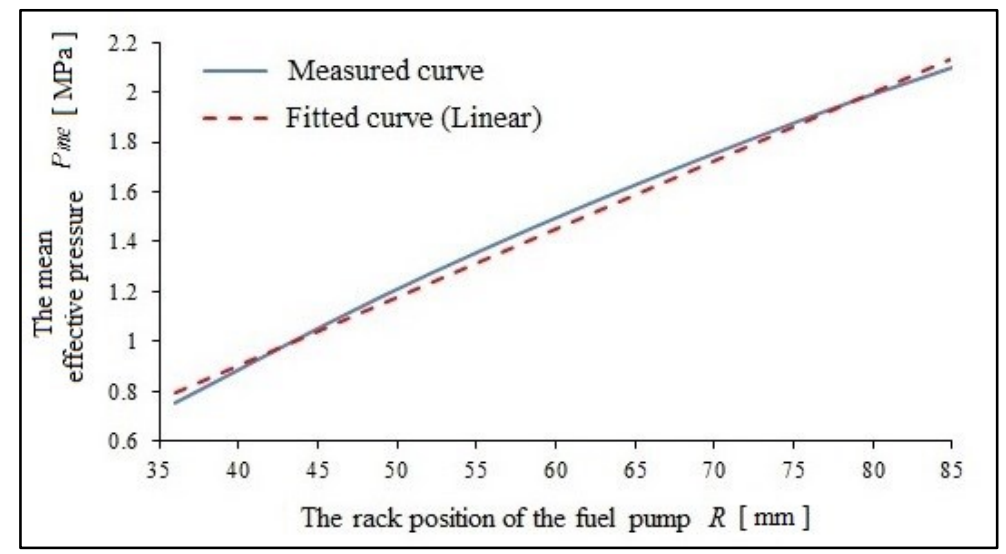

Figure 6. The relation between $p_{m e}$ and $R$

\section{(2) MAP.2 (m2)}

According to the different control purpose, the control algorithm (mode) is manually selected, that is, one of the three control algorithms of $\operatorname{LCD}\left(P_{e}\right), \operatorname{MEP}\left(p_{m e}\right)$ and $\operatorname{RPM}(n)$ is selected to control the injection frequency. It must be noted that the speed control algorithm should be used when the engine load is less than $25 \%$, in particular, slow steaming has become more of a normal operating procedure. In this condition, the cylinder oil is mainly required for liner lubrication instead of needing to consider the neutralization effect of the combustion products, as shown in Figure 7. This is because the engine operates according to the propulsion characteristic when the engine is directly connected to the propeller.

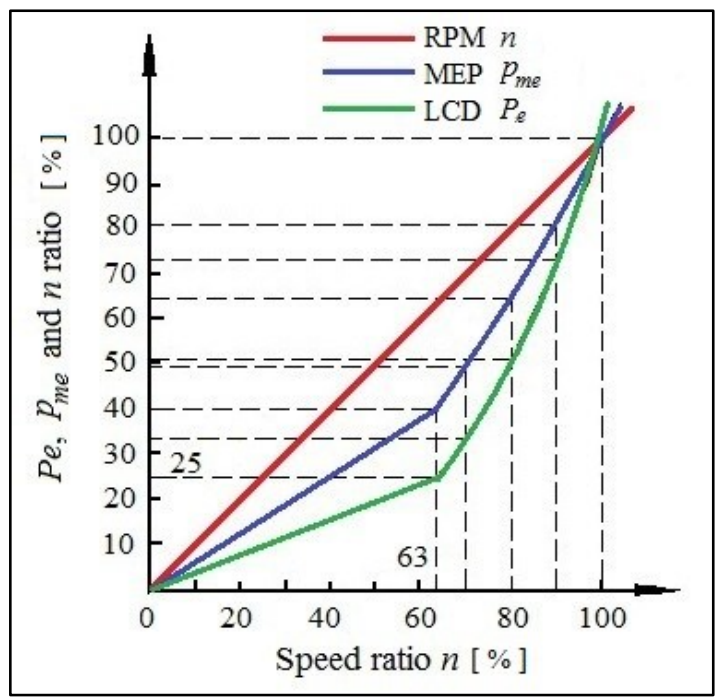

Figure 7. The relationship between $P_{e}, p_{m e}$ and $n$ in the condition of propulsion characteristic 
Various control algorithms are stored in the control program, as shown in equations (1), (2), (3) and (4). In addition, the engine rated speed $n_{e}$ also needs to be input, which is a constant for a specific type of engine and will not change after setting.

$$
\begin{aligned}
& \text { LCD }\left(P_{e}\right) \text { mode: } C_{\mathrm{pe}}=1 \\
& \operatorname{MEP}\left(p_{m e}\right) \text { mode: } C_{\mathrm{pme}}=1 /(n \%) \\
& \operatorname{RPM}(n) \text { mode: } C_{\mathrm{n}}=1 /(n \%)^{2} \\
& \quad n \%=n / n_{\mathrm{e}}
\end{aligned}
$$

Here, $C_{\mathrm{pe}}, C_{\mathrm{pme}}$ and $C_{\mathrm{n}}$ denote the coefficient of LCD, MEP and RPM control mode, respectively. $n$ and $n_{\mathrm{e}}$ are the engine speed and the engine rated speed, respectively, and $n \%$ denotes the speed rate.

By setting a parameter ' $n_{e}$ ', selecting one algorithm of LCD、MEP and RPM mode, inputting a variable ' $n$ ' measured by the crankshaft encoder, and outputting the coefficient of control mode ' $C$ ', as a result, MAP.2 can be obtained. Figure 8 is an example of a type of engine.

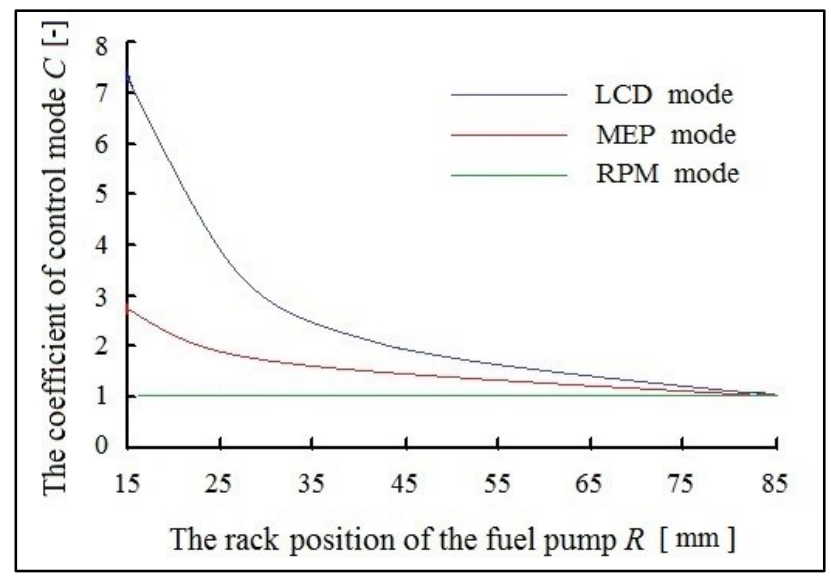

Figure 8. Coefficients $C$ in different control modes

\section{(3) MAP.3 (m3)}

The selection of cylinder oil depends mainly on the quality of fuel oil (especially sulphur content), cylinder oil quality (especially the TBN) and viscosity (affecting fluidity and lubrication effects), level of engine power density, scavenging type, and so on. Generally, the types of fuel oil and cylinder oil used in ships cannot be easily changed. As a rule, when the sulphur content of H.F.O is more than $2.5 \%$, a cylinder oil with TBN 65 70 should be used; when it is less than $2.5 \%$, the TBN is about 40 ; while the TBN is about $10-14$ for the normal diesel. $^{46,47}$

According to the acid-base neutralization reaction and existing experience: ${ }^{46,47}$ for every $1 \%$ increase in the sulphur content of the fuel oil, the COFR increases by $0.34-0.26 \mathrm{~g} /(\mathrm{kW} \cdot \mathrm{h})$. Equation 5 shows that the cylinder oil amount should be proportional to the amount of sulphur entering the cylinder with the fuel. However, the minimum COFR $g_{1 \min }$ should not be lower than 0.7-0.6 $\mathrm{g} /(\mathrm{kW} \cdot \mathrm{h})$. As shown in equation 6 , a minimum cylinder oil dosage is set to allow for other functions of the cylinder oil (securing sufficient oil film, detergency, etc.).

$$
\begin{aligned}
& g_{1}=0.34 \sim 0.26 \times S \% \\
& g_{1 \min }=0.7 \sim 0.6
\end{aligned}
$$


Where $g_{1}$ and $g_{1 \text { min }}$ denote the basic COFR and the minimum COFR, respectively. Also, $S \%$ is the sulphur content in fuel oil.

By selecting a parameter ' $S(\%)$ ' according to the sulphur content in the fuel (manual input) and outputting a parameter ' $g_{1}$ ', as a result, MAP.3 can be obtained. As shown in Figure 9, control of cylinder oil dosage is proportional to the sulphur percentage in the fuel, which is based on a standard TBN 70-80 cylinder oil.

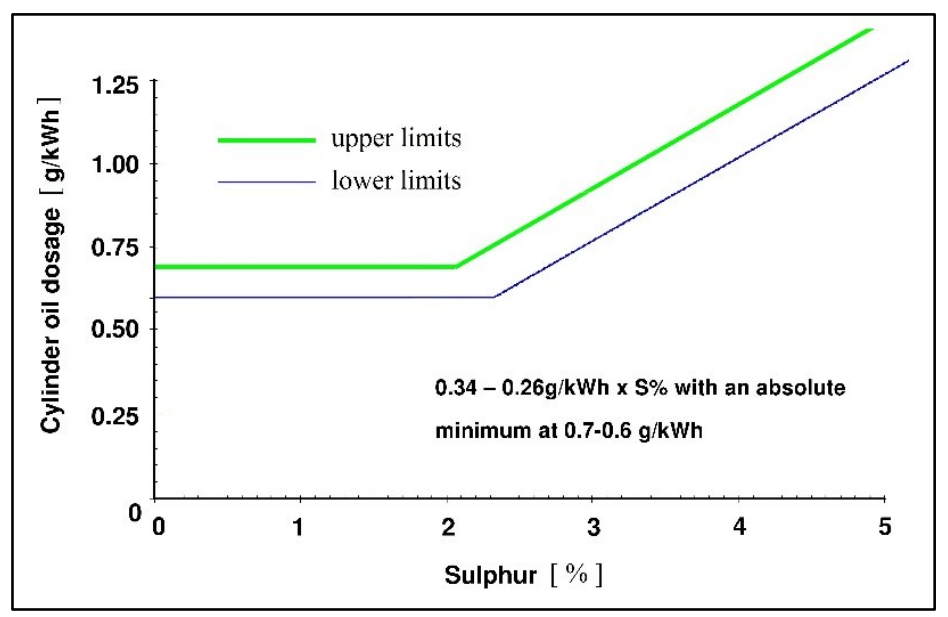

Figure 9. Cylinder oil dosage proportional to the sulphur content in the fuel

\section{(4) MAP.4 (m4)}

The definition of the running status coefficient $K$ is the running-in status of the cylinder liner and the piston ring. When a new cylinder liner is just installed to wear in, $K$ is defined as $200 \%$, and it is then defined as $100 \%$ after running-in. Therefore, each cylinder has a running status coefficient $K$ that can be independently adjusted.

According to the running status of the cylinder liner and piston ring, a coefficient $K$ can be obtained when manual inputting a parameter of the running time. The MCU will automatically record the running time and adjust the coefficient $K$ in time. As a result, MAP. 4 can be obtained. Figure 10 is an example of the running status coefficient $K$ of the cylinder liner and the piston ring. 


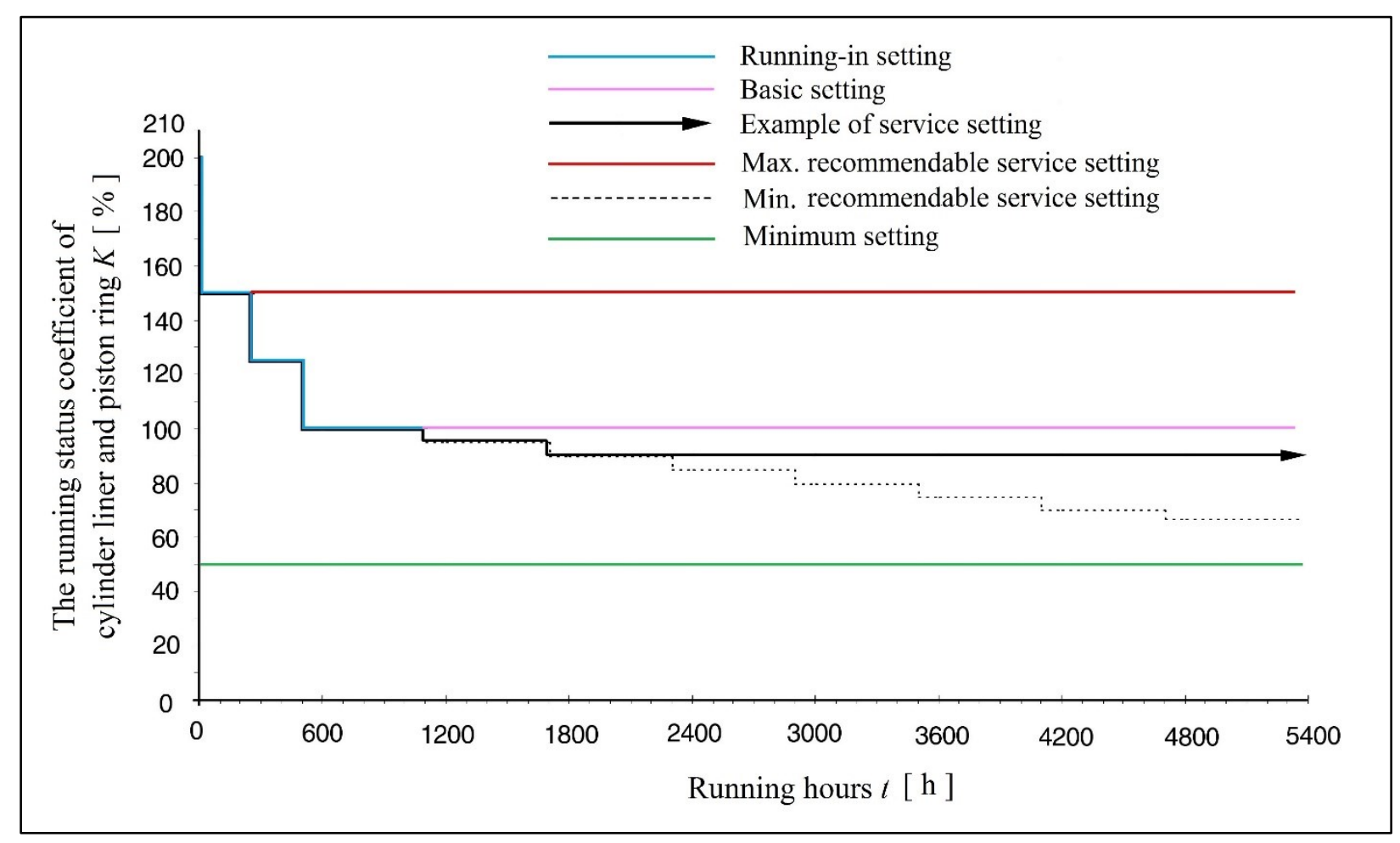

Figure 10. The running status coefficient of the cylinder liner and piston ring $K$

\section{(5) MAP.5 (m5)}

The basic COFR $g_{1}$ is corrected by the running status coefficient $K$. The corrected COFR $g_{2}$ is calculated according to equation (7) with the minimum to be not less than $0.60 \mathrm{~g} /(\mathrm{kW} \cdot \mathrm{h})$, the maximum not to exceed 1.65 $\mathrm{g} /(\mathrm{kW} \cdot \mathrm{h})$ after the running-in, as shown in equations (8) and (9).

$$
\begin{aligned}
& g_{2}=g_{1} \times K \\
& g_{2 \min }=0.6 \\
& g_{2 \max }=1.65
\end{aligned}
$$

Where $g_{2}$ denotes the COFR corrected by the coefficient of running status while $g_{2 \min }$ and $g_{2 \max }$ are the minimum COFR and maximum COFR, respectively.

An output parameter ' $g_{2}$ ' can be obtained by inputting a parameter ' $g_{1}$ ' and a coefficient ' $K$ '. The MCU will automatically record the running time and adjust the running status corrected COFR $g_{2}$ in time, as shown in Figure 11. Cylinder condition must be confirmed before adjustment, and the actual cylinder oil supplied should be measured after adjustment. 


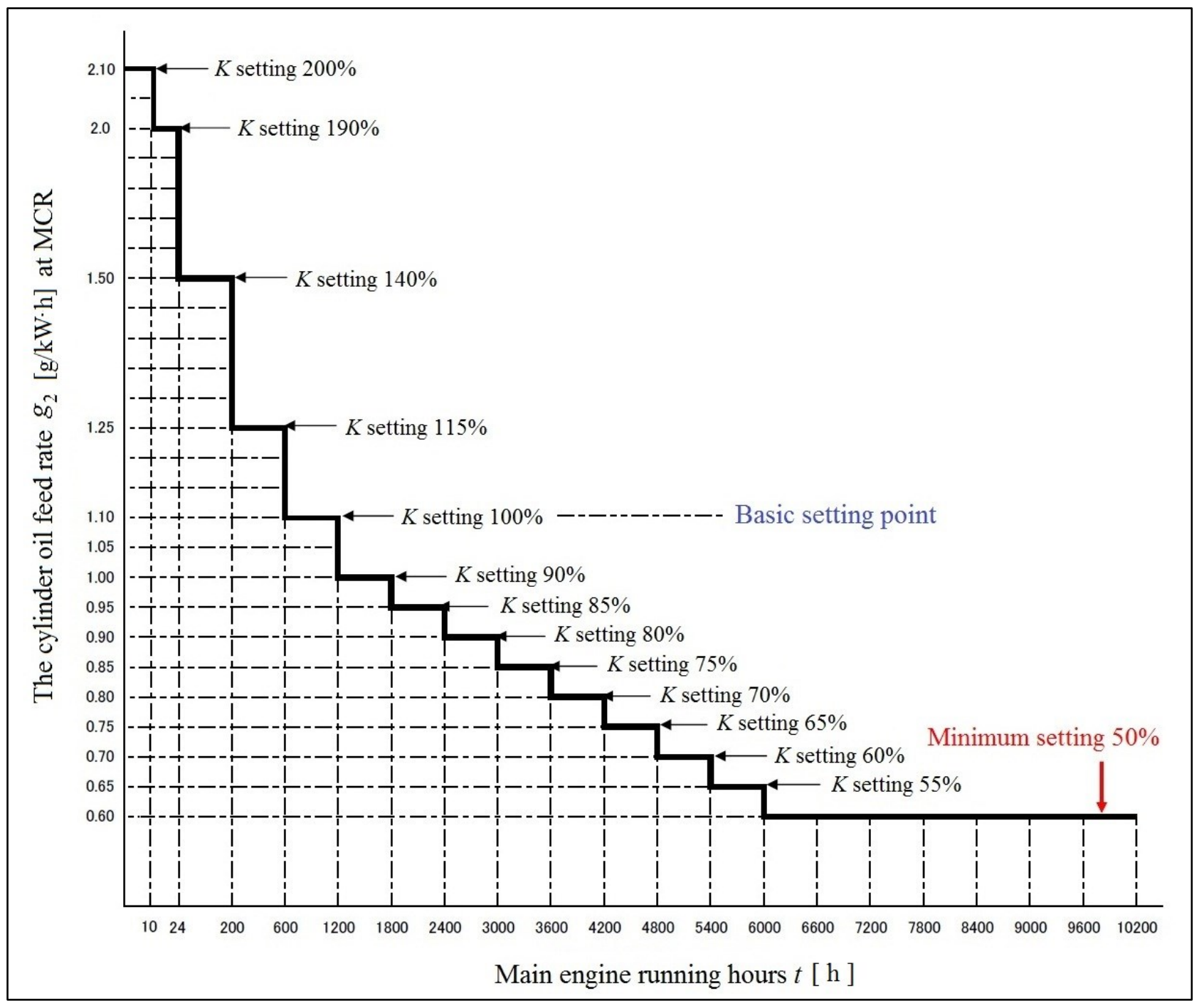

Figure 11. The COFR $g_{2}$ corrected by running status coefficient

\section{(6) MAP.6 (m6)}

The COFR $g_{3}$ is corrected by the coefficient of control mode, and calculated according to the control algorithm coefficient $C$, as shown in equation (10).

$$
g_{3}=g_{2} \times C
$$

Here, $C$ is the coefficient of control mode, one of $C_{\mathrm{pe}}, C_{\mathrm{pme}}$ and $C_{\mathrm{n}}$. And $g_{3}$ is the COFR corrected by the coefficient of control mode.

An output parameter ' $g_{3}$ ' can be obtained by inputting a parameter ' $g_{2}$ ' and a coefficient ' $C$ '.

\section{(7) MAP.7 (m7)}

Observations from a number of vessels with cylinder wear rates above the average show that the automatic increase of oil at start up and during load changes has reduced the wear rates. The new electronically controlled lubrication system features load dependence controlled by the frequency of the stepping motor. The lubricator offers automatically more cylinder oil during the process of load change. During starting, manoeuvring and load changes, regulation proportional to LCD or MEP should be replaced by RPM control mode, and the dosage increased by $25 \%$, as shown in equation (11). When the load is constant, a lower oil consumption will be 
recommended and with protection for the cylinder liners with load changes, and this type is widely applied, as shown in equation (12).

Frequent scavenge port inspections of the piston rings and cylinder liners are very important in maintaining good cylinder conditions. If irregularities are seen, adjustments of the COFR should be considered. In case of scuffing, sticking piston rings or high liner temperature fluctuations, the COFR should be raised by 50\%, as shown in equation (13).

By securing automatically increased lubrication during load changes improves the operating and wear conditions of the cylinder liners and piston rings. The new system, however, also permits one or more lubricators to be locked in minimum or maximum COFR while the remaining ones are operating automatically. As shown in equation (14) and (15).

$$
\begin{aligned}
& g_{4}=g_{3} \times 1.25 \\
& g_{4}=g_{3} \\
& g_{4}=g_{3} \times 1.50 \\
& g_{4 \min }=0.6 \\
& g_{4 \max }=2.10
\end{aligned}
$$

Where $g_{4}$ denotes the final COFR while $g_{4 \min }$ and $g_{4 \max }$ are the minimum COFR and the maximum COFR, respectively.

\section{(8) MAP.8 (m8)}

The cylinder oil injection quantity per cylinder and per cycle is defined as $q$ (g/str.cyl), which is a constant for a specific type of engine and will not require any change after setting. It is determined by the basic COFR, the basic injection frequency, structure and performance parameters of the engine, as shown in equation (16). Then, the oil injection frequency $f$ (rev. /inj.) is calculated by equation (17).

$$
\begin{aligned}
& q=\frac{P_{e} \cdot g_{1} \cdot f_{1}}{60 \cdot i \cdot n_{e}} \\
& f=\frac{7.2 \cdot q \cdot \tau}{\pi \cdot D^{2} \cdot S \cdot p_{m e} \cdot g_{4}} \times 10^{9}
\end{aligned}
$$

Here, $P_{\mathrm{e}}$ is the engine rated power, $g_{1}$ is the basic COFR and $g_{4}$ is the final COFR. $f_{1}$ denotes the basic injection frequency, and it's usually 3,4 or 5 rev./inj. $f$ is injection frequency. $i$ is the number of cylinders. $n_{\mathrm{e}}$ is the engine rated speed. $q$ denotes the oil injection quantity per cylinder and per cycle. $\tau$ is the number of engine stroke, and it's usually 2 or $4 . D$ is the cylinder diameter and $S$ is the engine stroke. $p_{\mathrm{me}}$ is the mean effective pressure.

An output variable ' $f$ (rev. /inj.)' can be obtained by inputting a variable ' $p_{\text {me }}$ ' (provided by MAP.1) and a parameter ' $g_{4}$ ' (provided by MAP.7). As a result, MAP.8 can be obtained. Figure 12 is an example of injection frequency for one type of engine. The maximum injection frequency is locked at 8 in order to avoid poor lubrication caused by a long period without cylinder oil, and the RPM control mode must be used when the engine load is less than $25 \%{ }^{48}$ 


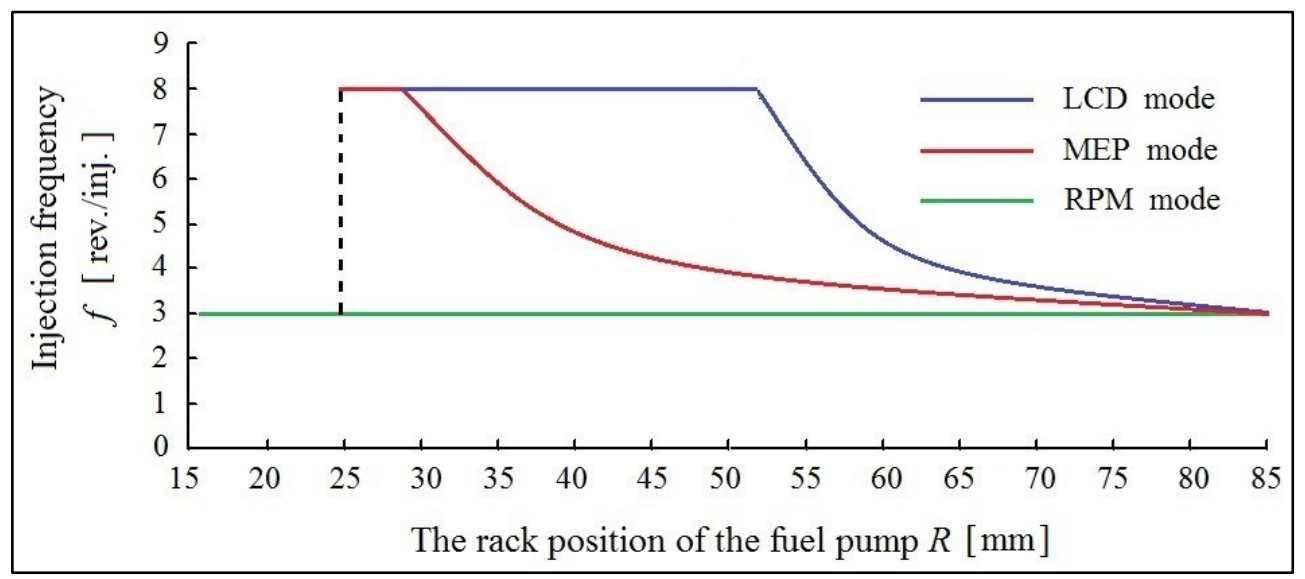

Figure 12. An example of injection frequency

The stepping motors may, when needed, be locked with a fixed-frequency of increased lubrication, e.g. during running-in of new cylinder liners, pistons or piston rings, the stepping motors are locked independently to deliver an increase in frequency. The other lubricators may still be operated automatically by the LCD, MEP or RPM regulation. When the period of increased lubrication is over, the fixed-frequency of the driver is switched off, which then changes the frequency of the stepping motor. Thereby the frequency in the lubricator is returned to the original setting.

(9) MAP.9 (m9)

Query the frequency allocation table according to the $f$-value, as shown in Table 1 (part).

Table 1. The frequency allocation table (part)

\begin{tabular}{ccc}
\hline$f$ (rev. /inj.) & Injections & Revolutions \\
\hline 1 & 10 & 10 \\
1.3 & 10 & 13 \\
1.8 & 10 & 18 \\
2.1 & 10 & 21 \\
2.7 & 10 & 27 \\
2.8 & 10 & 28 \\
3 & 10 & 30 \\
3.4 & 10 & 34 \\
3.7 & 10 & 37 \\
4 & 10 & 40 \\
5 & 10 & 50 \\
6 & 10 & 60 \\
7 & 10 & 70 \\
$\ldots$ & $\ldots$ & $\ldots$ \\
8 & 10 & 80 \\
\hline
\end{tabular}




\section{(10) MAP.10 (m10)}

According to the frequency allocation table 1 , the rotation speed $n$ and the BDC or TDC signal, the MCU sends a control pulse signal to the stepping motor driver to activate the lubricator to inject.

Lubricators equipped for LCD, MEP or RPM regulation of the cylinder oil quantity are fitted with a stepping motor to allow automatic injection frequency adjustment. Apart from this, a control system controlling the stepping motors is required, e.g. driver, control box and sensors or other equipment intended for the same function.

\subsection{Reliability}

\subsubsection{Dual redundant mechanism}

Due to poor working conditions, electromagnetic interference and other factors, it is particularly important to improve the reliability of the control system and to ensure that the measurement and control system is stable and running correctly. The system uses a dual-CPU redundancy designed to solve this problem, with a fault tolerant system (FTS) for dual-engines including two-MCUs to achieve the common standby and the mutual switch for the dual-engines.

This is a non-vote dual-redundant system. One CPU is regarded as a hot backup of the other one, and all tasks are run synchronously on two CPUs. All input signals are sent to both CPUs through the input interface at the same time, but the output of the CPU processing and handling is controlled by the arbitration of the switching circuit, and only the main CPU is allowed to read and write to the external data memory and output to an external device. When the main CPU fails, the system self-test switch logic will send out a signal, automatically cutting off its output channels, and alarm through the working instruct system of the CPU. At this point, the system automatically or manually switches over to another backup CPU and opens the output channel at the same time. The backup machine turns into the host operating status, and the control system is downgraded to run as a standalone at this time. The original host can be pulled out from the system for maintenance. A schematic of the Dual CPU control system is shown in Figure 13.

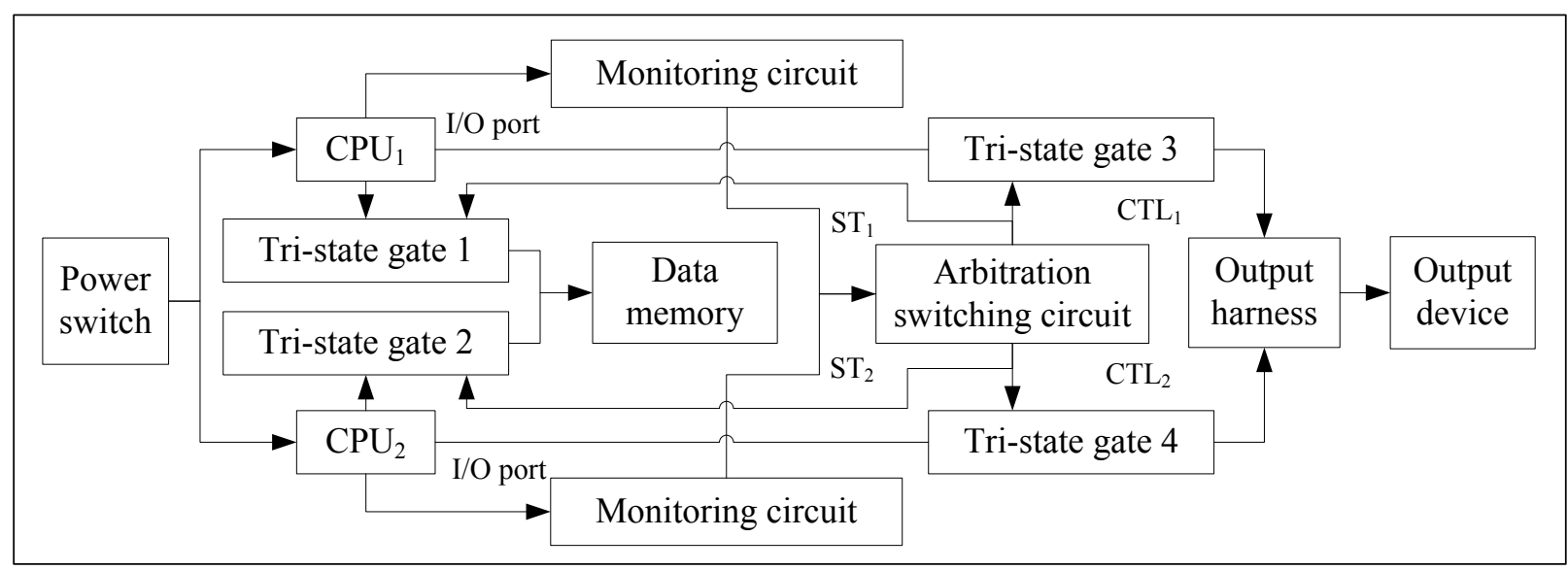

Figure 13. Schematic of Dual CPU control system 


\subsubsection{No-flow Alarm}

The introduction of a negative feedback pressure switch can not only amend the delay time but also produces a no-flowing signal. After the control signal of the stepper motor is sent out, the pressure switches will send out signals within $100 \mathrm{~ms}$ in normal circumstances. Pipeline leak, low oil pressure, or the stepper motor damage will cause no cylinder oil injection, and the pressure switch won't send a feedback signal to the controller. In this case, no-flow happened, and the controller will send a no-flow signal to the alarm panel. The control system will send out an alarm and follow up treatments will be activated.

\subsubsection{Mode switching}

The controller works independently. When the host computer malfunctions, the backup activates to give oil injection automatically. The electronic control/machine control module is switched by a dedicated logic circuit. When the controller output signal disappears, it will switch to the mechanical lubricator automatically.

\section{Experimental verification}

The aim of the verification programme is to determine whether the control strategies are correct or not when taking advantage of the new electronically controlled lubrication system. An added benefit of the new lubrication system is that savings in cylinder oil consumption will reduce the environmental impact from operating vessels. Also more uniform and optimal cylinder liner wear rates can be expected.

\subsection{Experimental condition}

The new ECCLS was fully tested in the laboratory, together with calibration work, prior to the actual ship commissioning test. As a retrofit on vessels in service, this system has been fitted to more than 120 main engines. Now, taking the vessel "GREAT GLEN" of Sinotrans Shipping Management Co., Ltd as the trial ship. The ship was fully loaded and cruised at a constant speed, and the verification test conditions are shown in Table 2 . The original mechanical lubricator was set to standby status, and cylinder lubrication carried out under the new ECCLS, the parameters of the main engine shown in Table 3. During the period of test, the operating parameters of the main engine are normal and stable, and the oil injection pressure, timing, frequency and cylinder oil consumption were recorded.

Table 2. The verification test conditions

\begin{tabular}{llll}
\hline Parameter & Variables & Unit & Value \\
\hline Ship name & - & - & GREAT GLEN \\
Sea condition & - & - & 5 (Rough) \\
Air classification & - & - & 6 \\
Wind direction & - & - & NEX \\
Course & - & $\left(^{\circ}\right)$ & 25 \\
Slip rate & - & $\%$ & 18.5
\end{tabular}




\begin{tabular}{llll}
\hline Parameter & Variables & Unit & Value \\
\hline Stem draft & - & $\mathrm{m}$ & 14.90 \\
Stern draft & - & $\mathrm{m}$ & 15.20 \\
Navigation speed & $V$ & $\mathrm{knot}$ & 11.04 \\
Engine compartment temperature & $T_{a}$ & ${ }^{\circ} \mathrm{C}$ & 38 \\
\hline
\end{tabular}

Table 3. The parameters of the main engine

\begin{tabular}{llll}
\hline Parameter & Variables & Unit & Value \\
\hline Engine type & - & - & MAN B\&W 6S60MC \\
Rated power & $P_{e}$ & $\mathrm{~kW}$ & 12240 \\
Rated speed & $n_{e}$ & $\mathrm{rpm}$ & 105 \\
Normal continuous rating (NCR) & $P_{n c r}$ & $\mathrm{~kW}$ & 10404 \\
Service speed & $n_{s}$ & $\mathrm{rpm}$ & 99.5 \\
Number of strokes & $\tau$ & - & 2 \\
Number of cylinders & $i$ & - & 6 \\
Cylinder diameter & $D$ & $\mathrm{~mm}$ & 600 \\
Piston stroke length & $S$ & $\mathrm{~mm}$ & 2292 \\
Number of oil quills (nozzles) per cylinder & $j$ & - & 6 \\
Cylinder oil injection quantity per cylinder and cycle & $q$ & $\mathrm{~g} / \mathrm{str} . c y l$ & 0.8587 \\
The running status coefficient & $K$ & $\%$ & 100 \\
Measured speed of the main engine & $n$ & $\mathrm{rpm}$ & 83.95 \\
Measured power of the main engine & $P_{s}$ & $\mathrm{~kW}$ & 6255.7 \\
Fuel index of fuel pump & $R$ & - & 60 \\
H.F.O consumption per day & $m_{f u e l}$ & ton/Day & 29.97 \\
Sulphur content in the H.F.O & $S$ & $\%$ & 3.37 \\
TBN of cylinder oil & $T B N$ & - & 70 \\
Viscosity index (VI) of cylinder oil & $V I$ & - & 50 \\
\hline
\end{tabular}

\subsection{Experimental apparatus}

During the operation of the new ECCLS, two pressure signals and two position signals were measured in the course of an oil injection cycle. At the same time, the oil injection frequency, engine speed and power were recorded and the COCR and ratio of cylinder oil saving were calculated.

\subsubsection{Oil pressure measurement}

The pressure signals were obtained from two pressure sensors. One was mounted at the inlet of the nozzle and used to measure the injection pressure. The other was mounted in the existing holes for the nozzles to measure the oil quill pressure, which is cylinder gas pressure at lubricating level (near the nozzle). Kistler piezoelectric pressure sensors were used in this test, and their main specifications are shown in table 4. 
Table 4. The main specifications of pressure sensors

\begin{tabular}{lll}
\hline Parameter & Sensor Properties & \\
\cline { 2 - 3 } & Injection pressure sensor & Oil quill pressure sensor \\
\hline Type & Type $601 \mathrm{CBA} 00070.0$ & Type $601 \mathrm{CBA} 00014.0$ \\
Sensitivity & $71 \mathrm{mV} / \mathrm{bar}$ & $357 \mathrm{mV} / \mathrm{bar}$ \\
Linearity & $\leq \pm 1.0 \% \mathrm{FSO}$ & $\leq \pm 1.0 \% \mathrm{FSO}$ \\
Operating temperature range & -55 to $+120{ }^{\circ} \mathrm{C}$ & -55 to $+120{ }^{\circ} \mathrm{C}$ \\
Natural frequency & $>215 \mathrm{kHz}$ & $>215 \mathrm{kHz}$ \\
Temp. coefficient of & $\approx+0.008 \% /{ }^{\circ} \mathrm{C}$ & $\approx+0.008 \% /{ }^{\circ} \mathrm{C}$ \\
sensitivity $\left(25\right.$ to $\left.120{ }^{\circ} \mathrm{C}\right)$ & & \\
Supply voltage & 22 to $30 \mathrm{VDC}$ & 22 to $30 \mathrm{VDC}$ \\
Output voltage (FSO) & $\pm 5 \mathrm{~V}$ & $\pm 5 \mathrm{~V}$ \\
\hline
\end{tabular}

\subsubsection{Rotational speed and position measurement}

The piston position signal was from a magnetoelectricity transducer which was mounted on the flywheel. Rotational speed and BDC signal were from an incremental shaft encoder which was mounted on the free end of the engine crankshaft. Model 758 incremental shaft encoder was used in this test. It is a heavy duty, extremely rugged, reliable encoder, designed for harsh engine room environments. Shaft loading is no problem for the doubleshielded ball bearings, and their $36 \mathrm{~kg}$ maximum axial and radial shaft load rating ensures a long operating life. Its main features are shown in table 5.

Table 5. The main features of Model 758 incremental shaft encoder

\begin{tabular}{ll}
\hline Parameter & Sensor Properties \\
\hline Cycles Per Revolution & 3000 \\
Input Voltage & 4.75 to 24 VDC for temperatures between $70{ }^{\circ} \mathrm{C}$ to $100{ }^{\circ} \mathrm{C}$ \\
Input Current & $100 \mathrm{~mA}$ max with no output load \\
Input Ripple & $100 \mathrm{mV}$ peak-to-peak at 0 to $100 \mathrm{kHz}$ \\
Output Format & Incremental - Two square waves in quadrature with channel A \\
& leading B for clockwise shaft rotation. \\
Output Types & Open Collector $-100 \mathrm{~mA}$ max per channel \\
Max Frequency & $200 \mathrm{kHz}$ \\
Symmetry & $180^{\circ}\left( \pm 18^{\circ}\right)$ \\
Quad Phasing & $90^{\circ}\left( \pm 22.5^{\circ}\right)$ \\
Min Edge Sep & $67.5^{\circ}$ \\
Rise Time & Less than 1 microsecond \\
Accuracy & Instrument and Quadrature Error: $0.01^{\circ}$ mechanical $(0.6$ arc \\
& minutes $)$ from one cycle to any other cycle. \\
Protection grade & IP 67 \\
\hline
\end{tabular}

\subsubsection{Oil-consumption measurement}

Due to some movement of the hull during operation, the cylinder oil consumption cannot be measured from the level of the cylinder oil daily service tank. For this actual ship trial, a specialized oil consumption meter is fitted to 
give an accurate and automatic measurement of cylinder oil consumption. It has built-in a high-precision weighing sensor, a measuring tank and a thermostatic device which has the advantages of wide range, high precision and continuous measurement. The main technical indicators are shown in table 6.

Table 6. The main features of the specialized oil consumption meter

\begin{tabular}{ll}
\hline Parameter & Specifications \\
\hline Measuring method & Directly measured by weight \\
Measuring range & $0 \sim 50 \mathrm{~kg}$ \\
Output & 4 to $20 \mathrm{~mA}$ \\
Linearity & $\leq \pm 1.0 \% \mathrm{FSO}$ \\
Accuracy & $\pm 0.02 \%$ \\
Operating temperature range & -10 to $+120^{\circ} \mathrm{C}$ \\
Temperature Accuracy & $\pm 1^{\circ} \mathrm{C}$ \\
\hline
\end{tabular}

\subsection{Experimental results and analysis}

\subsubsection{Injection pressure and timing}

The oil injection pressure and timing were measured in the course of an oil injection cycle, as shown in Figure 14. It can be seen from the Figure 14 that the oil injection pressure at the nozzle is about $3.0 \mathrm{MPa}$ and starts to rise at the moment when the first piston ring passes through the nozzle. Furthermore, oil injection duration is $15{ }^{\circ} \mathrm{CA}$ or less, which means the cylinder oil injection concentrates into the piston ring pack. These properties fully ensure the good lubrication and neutralization.

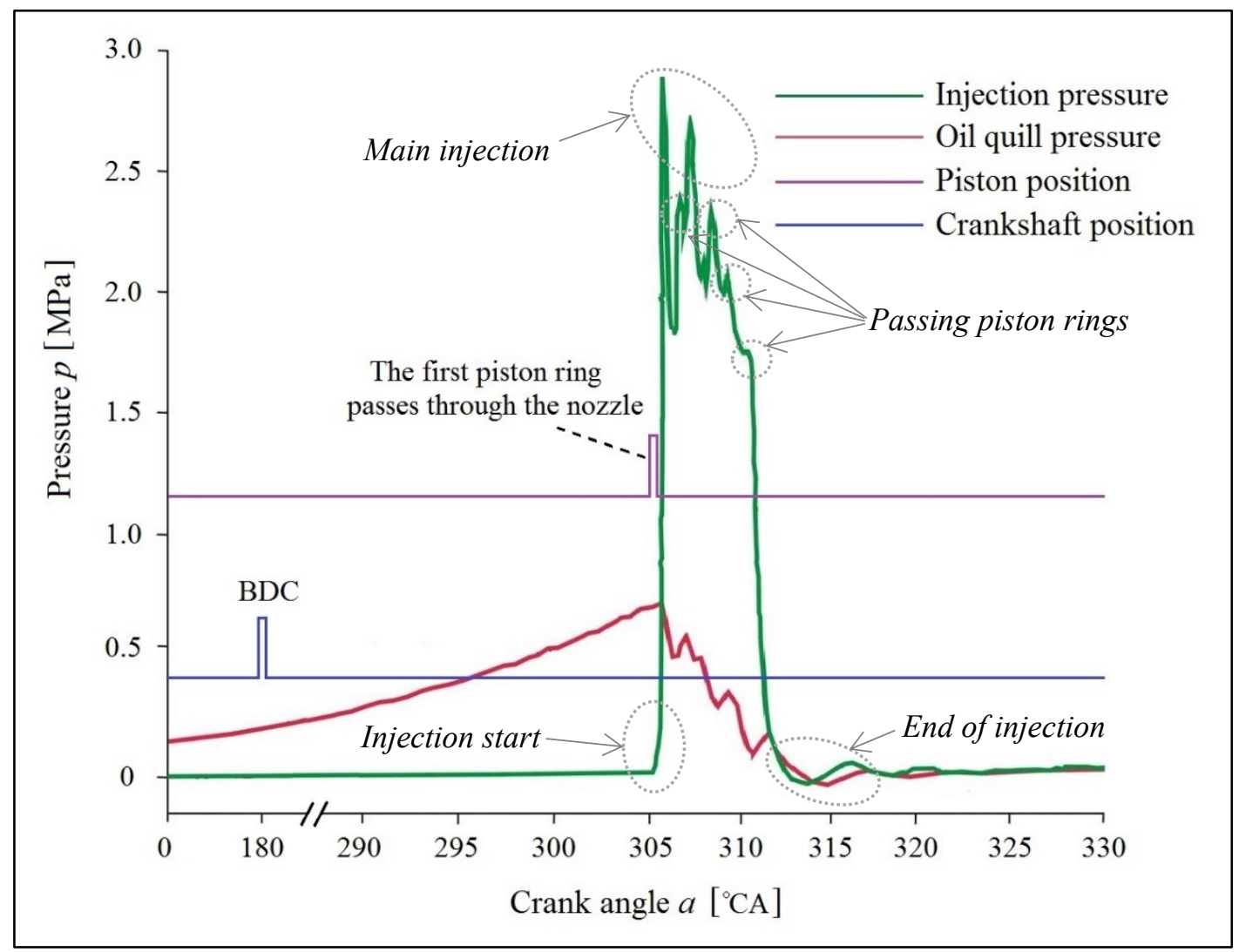


Figure 14. The timing curve between the cylinder oil pressure and BDC in a cycle of the engine

There are four interesting inflexion points in the injection pressure curve as shown in Figure 14. (1) Injection start: The driver of stepper motor receives the oil injection signal from the MCU and immediately drives the motor. Subsequently, the oil-pump starts to move, which in turn, moves their plungers in a reciprocating motion. The cylinder oil in the pipes starts to accelerate and the pressure rises. When the injection starting pressure of the nozzles is exceeded, the non-return valves open. (2) Main injection: Cylinder oil flow reaches the highest speed and all non-return valves are full open. At this stage, there is severe fluctuation in pressure due to interaction with the oil quill pressure and passing piston rings. (3) Passing piston rings: The green injection pressure curve shows four passing piston rings (see steps in the curve). The moment of injection pressure fluctuation is in one-to-one correspondence with the moment of oil quill pressure change and confirms each other. However, it still belongs to the stable injection. Injection is coming to an end as passing the last piston ring. (4) End of the injection: All the non-return valves are closing, and the pressure is still fluctuating a phenomenon in the pipes like a long train which starts to stop.

\subsubsection{Injection frequency}

In the verification tests, regardless of how the engine operating conditions are adjusted and other control variables are changed, the oil injection frequency is regulated automatically according to the engine load, the fuel sulphur content, TBN of cylinder oil, control mode, running status of cylinder liner and rings, etc. and the frequency change is to automatically and dynamically match the optimal COFR. Furthermore, the oil injection frequency adjustment range is locked in the range of $1 \sim 8$ to ensure the cylinder lubrication achieves the optimal COFR under a safe condition.

Under different operating conditions, the error of injection frequency between the measured and the theoretical calculation value does not exceed 2\%, as shown in Figure 15.

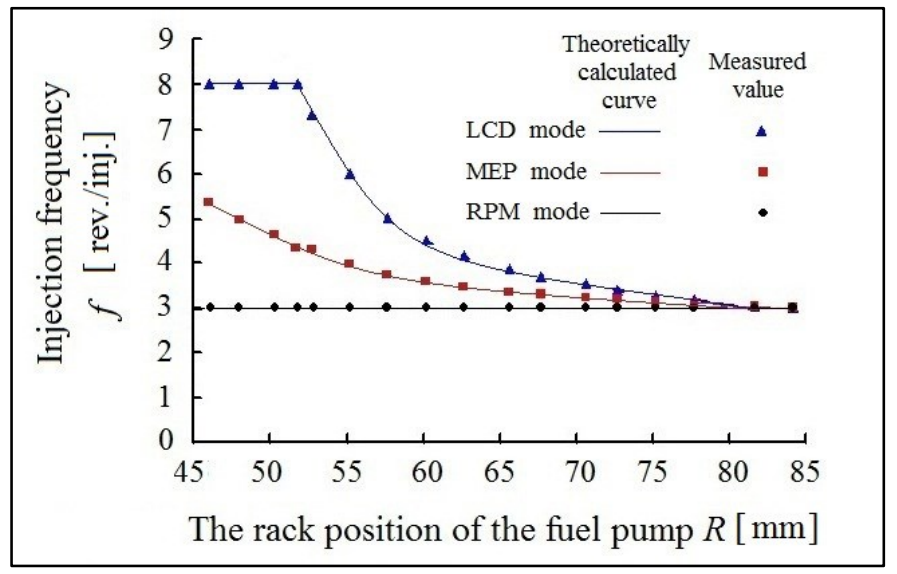

Figure 15. Oil injection frequency measured

\subsubsection{Injection quantity and cylinder oil consumption rate}

To explore the potential oil-savings with the new control strategies, a large-scale testing programme was initiated on MAN Diesel's MC and MC-C engines in service for a number of owners. The measuring results of 
cylinder oil consumption are shown in Table 7. As can be seen from Table 7, if this ship uses an ECCLS with the new control strategies, it can save 107.1 kilograms of cylinder oil per day under the $\operatorname{LCD}\left(P_{e}\right)$ control mode, which is equivalent to a saving of $54.3 \%$ compared with the original mechanical lubricator, and of greater significance is that reduced cylinder oil consumption means reducing particulate matter emissions, and accordingly protecting the environment. ${ }^{49}$ However, cylinder oil consumption will increase by $8.15 \%$ if RPM (n) control mode is applied, which is the same control method as with using the mechanical lubricator, and should be avoided.

Table 7. The comparison table of cylinder oil consumption measurement

\begin{tabular}{|c|c|c|c|c|c|c|}
\hline \multirow{2}{*}{\multicolumn{2}{|c|}{ Mechanical lubricator }} & \multirow{2}{*}{\multicolumn{4}{|c|}{$\begin{array}{l}\text { An electronically controlled Cylinder } \\
\text { lubrication system with the new control strategies }\end{array}$}} & \multirow{3}{*}{$\begin{array}{l}\text { Comparison } \\
\text { Ratio of } \\
\text { Cylinder oil } \\
\text { saving (\%) }\end{array}$} \\
\hline & & & & & & \\
\hline $\begin{array}{l}\text { Daily cylinder } \\
\text { oil consumption } \\
\text { (kg/Day) }\end{array}$ & $\begin{array}{l}\text { COCR } \\
(\mathrm{g} / \mathrm{kW} \cdot \mathrm{h})\end{array}$ & Control mode & $\begin{array}{l}\text { Oil injection } \\
\text { frequency } \\
\text { (inj./rev. ) }\end{array}$ & $\begin{array}{l}\text { Daily cylinder } \\
\text { oil consumption } \\
\text { (kg/Day) }\end{array}$ & $\begin{array}{l}\text { COCR } \\
(\mathrm{g} / \mathrm{kW} \cdot \mathrm{h})\end{array}$ & \\
\hline \multirow[t]{3}{*}{197.1} & 1.313 & $\operatorname{LCD}\left(P_{e}\right)$ mode & 7.1 & 90.0 & 0.60 & 54.30 \\
\hline & & $\operatorname{MEP}\left(P_{m e}\right)$ mode & 4.3 & 148.5 & 0.99 & 24.65 \\
\hline & & RPM $(n)$ mode & 3.0 & 212.9 & 1.42 & -8.15 \\
\hline
\end{tabular}

\subsection{4 lubrication effect}

When the engine is stopped, the exhaust valve and the scavenging box manhole opened to take pictures of the cylinder, as shown in Figure 16 and 17, which are photographs of the piston rings and the bottom of the scavenging box. Figure 16 shows the condition when using a mechanical lubricator and Figure 17 shows the situation when using an ECCLS with the new control strategies presented in this article. It can be seen from the pictures that no abnormal scratches were found on the cylinder wall, piston and piston rings. ${ }^{50}$

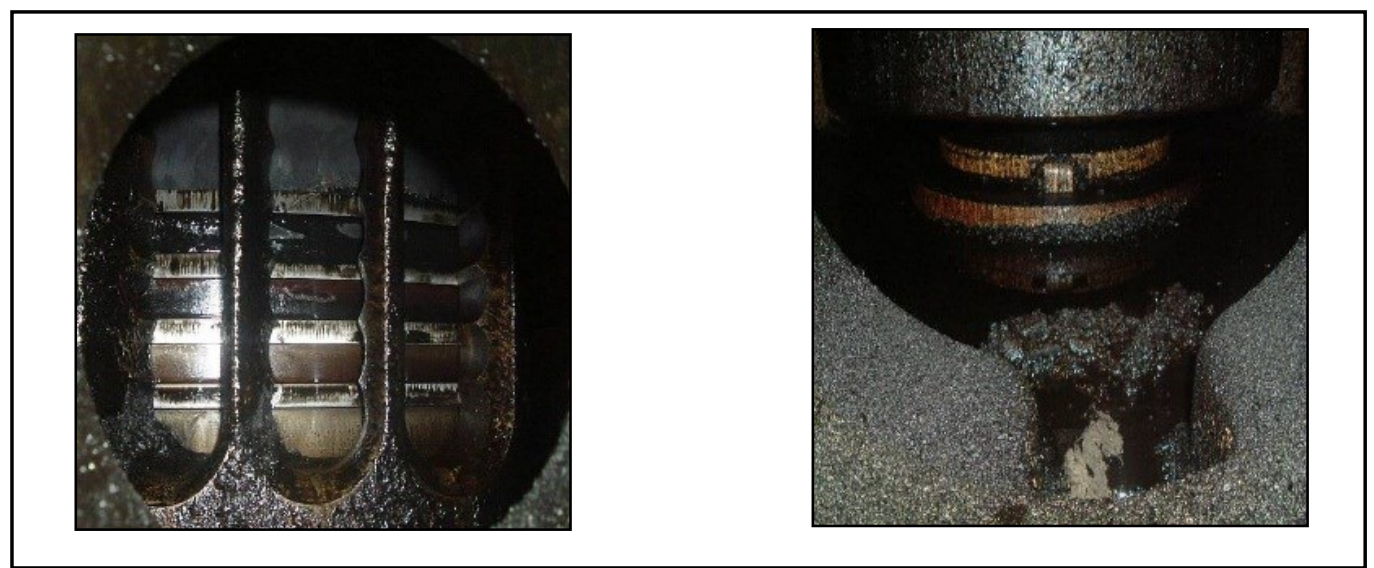

Figure 16. The piston rings and the bottom of scavenging box when using a mechanical lubricator 


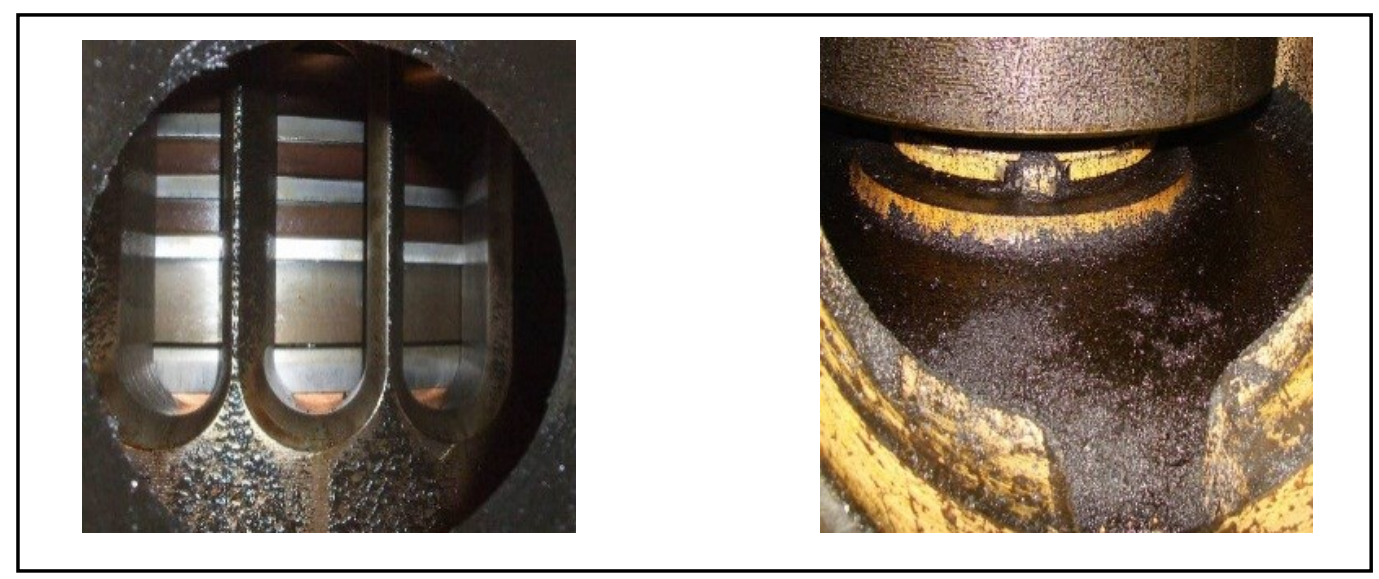

Figure 17. The piston rings and the bottom of scavenging box when using the new system

\subsubsection{Reliability}

Through a large number of fault simulation experiments, the following conclusions are reached:

(1) During normal operation, the system is controlled by the MCU. If any failures are detected in the system, a common alarm is activated in the control room. The detailed alarm reference is displayed on the HMI panel.

(2) If a critical failure in the MCU is detected, the SCU automatically takes over (Note: control switch must be in "auto" position). An indication lamp "SCU in control" is lit on the panel that contains the HMI panel. At the same time, the main engine automatically switches to "SLOW-DOWN" mode.

(3) A feedback signal from the switching device indicates that oil injection has taken place. This is shown by light emitting diodes (LED) on intermediate boxes for each cylinder.

(4) If the SCU also fails, the system may be restored to mechanical lubricator operation mode by the "electronically controlled/ machine-controlled" switching device.

\section{Conclusion}

Significantly improved thermal efficiency, fuel economy and ability to burn poor quality bunkers have resulted in an intensive development of low-speed crosshead engine designs in the past 20 years. Further progress in performance and enhanced lifetimes can be expected from the exploitation of higher firing pressures and better combustion characteristics. Such advances pose a continuing challenge to the engine CLS, however: higher pressures and temperatures make it more difficult to provide an oil film in the critical zones, ${ }^{51}$ and longer strokes (another design trend) lead to spreadability problems. The success of new generations of engines will, therefore, continue to depend on the quality of their cylinder lubrication. The control strategies developed and verified in this article can well meet the future requirements of cylinder lubrication. The main conclusions are listed as follows.

(1) The cylinder lubrication is based on a constant amount of oil being supplied per injection. The specific COFR is controlled by variation of the injection frequency. System flexibility makes it possible to choose any number of engine revolutions (three, four, five, six, etc.) between injections of a specific amount of oil into the cylinder. For example, lubrication can be effected every fifth revolution in the compression stroke and every eighth in the expansion stroke if that turns out to be optimal. 
(2) The MCU controls the oil injection by activating a stepping motor connected to the relevant lubricator. The injection frequency is calculated from engine load and speed and is normally proportional to the engine power (LCD mode). However, an MEP mode or RPM mode is possible. The cylinder oil amount can also be adjusted to match the sulphur content of marine fuels and TBN of cylinder oil. Furthermore, Adjustment of COFR for individual cylinders is possible between $50 \%$ and $200 \%$. The default value is $100 \%$.

(3) The cylinder oil injection timing is based on two signals from the crank angle's encoder. Through dynamic correction, it can ensure that every injection timing is at the target injection point, which ensures the precise injection timing, the appropriate quantity of cylinder oil and the optimal COFR for good lubrication and neutralization.

(4) The oil injection pressure is about 3.0 MPa, and oil is being injected at the critical stroke process of the piston to ensure the better performance for the cylinder. This enables oil consumption to become less than conventional low-pressure oil distribution, achieving the goal of energy conservation and emission reduction.

(5) The control strategy of system reliability offers great flexibility. Adopting maximum electronic and visual check method to ensure safety.

(6) Experience with the control strategy of ECCLS indicated that there was significant potential for cylinder lubrication oil reduction while retaining a fully acceptable wear rate and mean time between overhaul (TBO).

\section{Acknowledgements}

Authors are grateful to the School of Energy and Power Engineering at Wuhan University of Technology for the calculation support on the project. We also appreciate the Wuhan Sailinde Marine Technology Co., Ltd for providing experimental facilities and test data. Thanks to David Blenkison for improving the language of the manuscript. The authors appreciate the anonymous reviewers and the editor for carefully reading and providing many constructive comments and suggestions for enhancing the manuscript. The first author appreciates the Chinese Scholarship Council (CSC, No. 201706955099) and the Wuhan University of Technology for financial support for his Academic Visitor (AV) research in the University of Strathclyde.

\section{Funding}

The author(s) disclosed receipt of the following financial support for the research, authorship, and/or publication of this article: This research was supported by the project 'Verification Platform Research and Key Technology Development of Low-Speed Marine Diesel Engine (Ministry of Science and Technology No. 2015BAG16B01)' from Ministry of Science and Technology in China. And it was also supported by the project 'Engineering Development of Low-speed Marine Engine (the first phase) (Ministry of Industry and Information Technology No. [2017] 21)', the project 'Key Technologies Research on Civil Ship Propulsion Integration (Ministry of Industry and Information Technology No. [2009] 54)' and the project 'Domestic Development of SB35/40ME-B small-bore low-speed high-power marine diesel engine (Ministry of Industry and Information Technology No. [2009] 54)' from Ministry of Industry and Information Technology in China. This research was also financially supported and conducted in the Key Laboratory of Marine Power Engineering \& Technology under Minister of Communication PR China. 


\section{Declaration of conflicting interests}

The author(s) declared no potential conflicts of interest with respect to the research, authorship and/or publication of this article.

\section{Abbreviations/Notation}

$\begin{array}{ll}\text { ACC } & \text { Adaptive Cylinder-oil Control } \\ \text { AL } & \text { Alpha lubrication } \\ \text { AP } & \text { Accumulator Principle } \\ \text { BDC } & \text { Bottom Dead Centre } \\ \text { CLS } & \text { Cylinder Lubrication System } \\ \text { COCR } & \text { Cylinder Oil Consumption Rate } \\ \text { COFR } & \text { Cylinder Oil Feed Rate } \\ \text { ECCLS } & \text { Electronically Controlled Cylinder Lubrication System } \\ \text { E/M CSD } & \text { Electronical / Mechanical Control Switching Device } \\ \text { FTS } & \text { Fault Tolerant System } \\ \text { H.F.O } & \text { Heavy Fuel Oil } \\ \text { HJ } & \text { Hans Jensen } \\ \text { HJL } & \text { Hans Jensen Lubricator A/S } \\ \text { HMI } & \text { Human Machine Interface } \\ \text { LCD } & \text { Load Change Dependent } \\ \text { LED } & \text { Light Emitting Diodes } \\ \text { Lub.U } & \text { Lubricator Unit } \\ \text { MCR } & \text { Maximum Continuous Rating } \\ \text { MCU } & \text { Main Control Unit } \\ \text { MEP } & \text { Mean Effective Pressure } \\ \text { NCR } & \text { Normal Continuous Rating } \\ \text { OFU } & \text { Oil-feed Unit } \\ \text { PLS } & \text { Pulse Lubrication System } \\ \text { PM } & \text { Particulate Matter } \\ \text { RPM } & \text { Revolutions Per Minute } \\ \text { SCU } & \text { Standby Control Unit } \\ \text { SIP } & \text { Swirl Injection Principle } \\ \text { TBN } & \text { Total Base Number } \\ \text { TBO } & \text { Time Between Overhaul. } \\ \text { TDC } & \text { Top Dead Centre } \\ \text { TLS } & \text { Timed Lubrication System } \\ \text { VI } & \text { Viscosity Index } \\ & \end{array}$

\section{References}


1. Doug Woodyard. Introduction: A Century of Diesel Progress. In: Doug Woodyard (ed.) Pounder's Marine Diesel Engines and Gas Turbines. 9th ed. Oxford: Butterworth-Heinemann, 2009; pp.ix-xxvii.

2. Chen Shaogang, Zhu Guowei, Li Yuzhong and Shao Zude. The Marine Engineering Manual. The People's Communication Press, Beijing, 1992, p.21-32.

3. Chew F and McGeary T. Study of the relationship between cylinder lubricant drain condition and performance parameters of 2-stroke cross-head engines. CIMAC, Hamburg; 2001.

4. Zhang Xiaoming. An electronically controlled cylinder lubrication system applied to main engine in an actual ship. Chinese Ship Survey 2010; 08:54-55.

5. Gao Bing and Zhao Zhiqi. Application research and development trend analysis of cylinder lubrication technology for marine diesel engine. Energy Conservation \& Enviromental Protection in Transportation 2010; 04: 9-12.

6. Zheng Guojie, Cai Zhenxiong and Liu Jianhua. Analysis of cylinder lubrication technology of marine diesel engine. Tianjin Navigation 2009; 01:11-14.

7. Zhao Jiesheng. Adjustment of cylinder oil for MAN B\&W K90MC-C main engine. Marine Technology 2008; 01:53-56.

8. HeYuhai. Research on control strategy of electronically controlled cylinder lubrication system for marine diesel engine. Journal of Wuhan University of Technology 2010; 32(15):114-118.

9. Gao Bing. Simulation and Driving Toraue Experimental Research on the Electronicallv Controlled Cvlinder Lubricator. Master's Thesis, Wuhan University of Technology, Wuhan, China, 2009.

10. Chen Zhijun. Development and experimental research on new cylinder oil lubrication system for marine large low-speed two-stroke diesel engine. Doctor's Thesis, Wuhan University of Technology, Wuhan, China, 2015.

11. Zheng Weikang. Analysis of cylinder oil management from scavenging box fire in the initial stage of main engine operation. Marine Technology 2009; 01:63-64.

12. Xu Guoxin. A method for reducing the cylinder oil consumption rate for Alpha cylinder lubricator. Marine Technology 2016; 05: 42-44.

13. He Yuhai. Study on cylinder lubrication technology for marine engine. China Ship Repair 2010; 23(4):5-8.

14. Zhang Congde and Zhang DaZhi. Adjustment and analysis of cylinder oil feed rate for Alpha electronically controlled cylinder lubricator. China Water Transport 2014; 02:141-143.

15. Su Zhonglin. Study on cylinder liner wear and cylinder oil control. Marine energy saving 2002; 01:33.

16. Bao Junhui. An analysis of the irregular operation of indicating projectile for a main engine cylinder lubricator. Diesel Engine 2017; 02:51-52, 55.

17. Wu Quansheng and Han Qingchun. A failure example of a cylinder lubricator for the diesel engine. Marine Technology 2016; 02:50-52.

18. Mohamad Salaheldin A, Lu Xiqun and Zheng Qun. Numerical modeling of lubrication of piston ring of two-stroke marine diesel engine considering the effect of multi-scale grooves on the cylinder liner. P I Mech Eng J-J Eng 2015; 229(8):989-1002.

19. Chen Zhongru. Fundamentals and management of CLU-4 pulse feed lubrication system. Pearl River Water Transport 2014; 12:8-9.

20. Ling Gangyi and Deng Jianxing. New Generation of Electric Impulse Cylinder Lubrication System. Mechanical and Electrical Equipment 2013; 30(05):64-67.

21. Gao Bing. Alpha ACC electronically controlled cylinder lubrication system and its application. Marine Technology 2012; 04:48-51.

22. Yao shimin and Xu Jing. Introduction to the practical use of ALPHA electronically controlled cylinder 
lubricator. Marine Technology 2006; 03:50-52.

23. Yang Yongjian and Li Fuhai. Analysis of the advantages of an electronically controlled cylinder lubricator refitted on marine diesel engine. Journal of Qingdao Ocean Shipping Mariners College 2013; 03:13-15, 31.

24. Lu Lin and Gao Bing. Study on the control mechanism of electronic cylinder lubricator oil injection frequency modulation. Ship \& Ocean Engineering 2010; 39(01): 78-79, 83.

25. He Yuhai, Li Meng and Wang Qingpeng. Study on optimal design and practical use of an electronicallycontrolled cylinder lubricating system. Chinese Internal Combustion Engine Engineering 2016; 37(4):234240.

26. He Yuhai. Research on new electro-controlled cylinder lubrication system for large low-speed marine diesel engine. Chinese Internal Combustion Engine Engineering 2010; 31(04):63-68.

27. He Yuhai. Research on calibration tests of an electronically controlled cylinder lubrication system for a large low-speed marine diesel engine. Journal of Harbin Engineering University 2011; 32(4):411-416.

28. Chen Zhijun and Wu Danwen. Development of electronic control system for cylinder lubricator. Navigation of China 2012; 02: 20-23, 28.

29. Chen Zhijun. Design of electronic control system of cylinder lubricator for marine two-stroke engine. Journal of Wuhan University of Technology 2010; 32(15):95-98.

30. MAN B\&W Diesel A/S. Alpha Adaptive Cylinder-oil Control Alpha ACC. CIMAC CIRCLE SMM; 2002.

31. Cai Guanghui. Abnormal wear analysis of the piston rings and cylinder liner caused by improper oilinjection quantity. Marine Technology 2012; 05:55-57.

32. Shi qianghua and Shan Gaoyong. A failure analysis of ALPHA electronically controlled cylinder lubrication system. Marine Technology 2012; 03:54-58.

33. Wang Weifei. An important parameter that cannot be ignored in ALPHA electronic lubricator. Marine Technology 2011; 01:52-53.

34. Li Guowei. A brief fault analysis of ALPHA electronically controlled cylinder lubrication system for marine engine. Navigation 2012; 05:67-69.

35. Ren Baokun. Analysis and disposal measures for several minor faults in the newly installed Alpha ACC cylinder lubrication system. China Water Transport 2010; 11: 121-122.

36. Hu Gang. Management and improvement of Alpha electronic lubricator. Journal of Qingdao Ocean Shipping Mariners College 2016; 02:46-49.

37. Yang Xianming and Lu Yunji. A failure case of ALPHA electronically controlled cylinder lubricator. Marine Technology 2015; 03:50-51.

38. Wang lianhai, Wang Wenlong and Liang Hao. Analysis of No-flow alarm failure for an electronically controlled cylinder lubricator. Marine Technology 2014; 05:47-48.

39. Xiong Shifeng and Gao Bing. Common fault diagnosis and troubleshooting of ALPHA electronically controlled cylinder lubricator. Marine Technology 2014; 05:56-60.

40. Yan Wei and Zhu Yongxiang. Management and troubleshooting of Alpha cylinder lubrication system. Journal of Nantong shipping college 2010; 04:26-28.

41. Qi Wenzheng. Fault analysis of an electronically controlled cylinder lubrication system with low oil pressure and high oil temperature. Marine Technology 2014; 02:57-61.

42. Zhou Jiyu and Dong Jun. Analysis of an alarm failure of the high temperature for ALPHA electronically controlled cylinder lubrication system. Marine Technology 2012; 03:50-51.

43. Usman Ali and Park Cheol Woo. Modeling and simulation of frictional energy loss in mixed lubrication of a textured piston compression ring during warm-up of spark ignition engine. Int J Engine Res 2017; 18(4):293-307. 
44. Meng Xianghui, Gu Chunxing and Xie Youbai, et al. A two-dimensional starved lubrication analysis method for textured surfaces. Int J Engine Res 2016; 17(10):1062-1076.

45. Gu Chunxing, Meng Xianghui and Xie Youbai, et al. The influence of surface texturing on the transition of the lubrication regimes between a piston ring and a cylinder liner. Int J Engine Res 2017; 18(8):785-796.

46. MAN B\&W Diesel A/S. Cylinder lubrication update/Guiding ACC feed rate for Alpha lubricator and ME lube. Service Letter SL09-507/HRR 2009; Branch of MAN Diesel SE, Germany.

47. MAN B\&W Diesel A/S. Cylinder lubrication/New ACC Guidelines for all MC, MC-C and ME type engines with Alpha ACC system. Service Letter SL07-479/HRR 2007; Branch of MAN Diesel SE, Germany.

48. MAN B\&W Diesel A/S. Replacement of transparent polycarbonate covers. Service Letter SL2012-558/CHL 2012; Branch of MAN Diesel SE, Germany.

49. Cherng-Yuan Lin. Reduction of particulate matter and gaseous emission from marine diesel engines using a catalyzed particulate filter. Ocean Eng 2002; 29(11):1327-1341.

50. Gequn Shu, Lihui Dong and Xingyu Liang. A review of experimental studies on deposits in the combustion chambers of internal combustion engines. Int J Engine Res 2011; 13(4):357-369.

51. Stolarski T A, Zhou Q, Smart M, Green D and Allen R W. Temperature-friction characteristics of cylinder lubrication in large, slow, cross-head marine diesel engines under boundary lubrication conditions. Lubr Sci 2004; 16(4):337-346. 